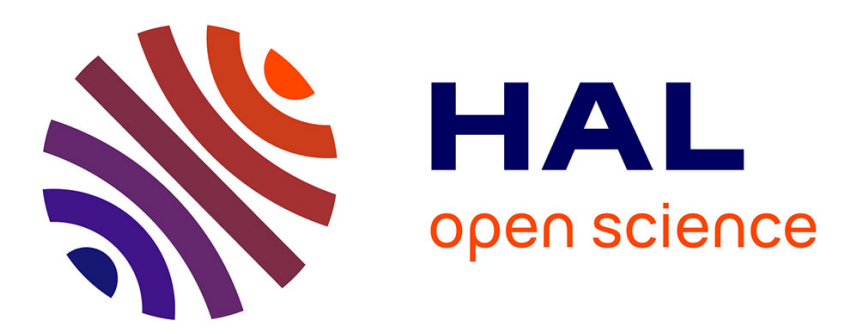

\title{
Phosphorhydrazones as Useful Building Blocks for Special Architectures: Macrocycles and Dendrimers
}

\author{
Jean Pierre Majoral, Anne-Marie Caminade
}

\section{To cite this version:}

Jean Pierre Majoral, Anne-Marie Caminade. Phosphorhydrazones as Useful Building Blocks for Special Architectures: Macrocycles and Dendrimers. European Journal of Inorganic Chemistry, 2019, 2019 (11-12), pp.1457-1475. 10.1002/ejic.201801184 . hal-02140457

\section{HAL Id: hal-02140457 \\ https://hal.science/hal-02140457}

Submitted on 2 Nov 2020

HAL is a multi-disciplinary open access archive for the deposit and dissemination of scientific research documents, whether they are published or not. The documents may come from teaching and research institutions in France or abroad, or from public or private research centers.
L'archive ouverte pluridisciplinaire HAL, est destinée au dépôt et à la diffusion de documents scientifiques de niveau recherche, publiés ou non, émanant des établissements d'enseignement et de recherche français ou étrangers, des laboratoires publics ou privés. 


\title{
Phosphorhydrazones as useful building-blocks for special architectures: macrocycles and dendrimers.
}

\author{
Jean-Pierre Majoral, ${ }^{[\mathrm{a}][\mathrm{b}]}$ and Anne-Marie Caminade ${ }^{\star[\mathrm{a}][\mathrm{b}]}$ \\ Dedicated to Prof. Dr. Koop Lammertsma on the occasion of his $70^{\text {th }}$ birthday and to Prof. Dr. Edgar Niecke on the occasion of his \\ $80^{\text {th }}$ birthday.
}

\begin{abstract}
The role of phosphorhydrazide derivatives in particular of type $\mathrm{RP}(\mathrm{X})\left(\mathrm{NMeNH}_{2}\right)_{2}$ for the synthesis of macrocycles, and of type $\mathrm{Cl}_{2} \mathrm{P}(\mathrm{X}) \mathrm{NMeNH}_{2} \quad(\mathrm{X}=\mathrm{O}, \mathrm{S}$ in both cases) for the synthesis of dendrimers will be shown in this review. In both cases, condensation reactions with different types of aldehydes (often aromatic) afford phosphorhydrazone derivatives, which are the building blocks for these special architectures. After the synthetic aspects, selected properties concerning catalysis, nanomaterials, and biology/nanomedicine will be displayed.
\end{abstract}

\section{Introduction}

Among the huge number of phosphorus derivatives that have been already synthesized, phosphorhydrazides, which comprise the fragment $(X) P N(R) N_{2}$, and phosphorhydrazones, which correspond to the condensation of this fragment with aldehydes (eventually ketones), have been successfully used for the synthesis of special macromolecular architectures. The first members of this family have been synthesized more than one century ago for $\mathrm{X}=\mathrm{O}$ by reaction of $\mathrm{P}-\mathrm{Cl}$ functions with hydrazine derivatives, affording the first phosphorhydrazide derivatives, in particular $\mathrm{Cl}_{2} \mathrm{CHCONHP}(\mathrm{O})(\mathrm{NHNHPh})_{2}$ from phenylhydrazine, ${ }^{[1]}$ and $(\mathrm{PhO})_{2} \mathrm{P}(\mathrm{O}) \mathrm{NHNH}_{2}$ from hydrazine. ${ }^{[2]}$ Derivatives of thiophosphorhydrazide $(X=S)$ have been synthesized slightly later, to produce in particular $\operatorname{PhOP}(\mathrm{S})\left(\mathrm{NHNH}_{2}\right)_{2}, \quad \quad \mathrm{MeC}_{6} \mathrm{H}_{4} \mathrm{OP}(\mathrm{S})\left(\mathrm{NHNH}_{2}\right)_{2}, \quad$ and $\mathrm{EtO}(\mathrm{OH}) \mathrm{P}(\mathrm{O}) \mathrm{NHNH}_{2}{ }^{[3]}$ also by reaction with hydrazine.

Methylhydrazine was used later for the synthesis of phosphorhydrazides, but problems were experienced, such as the difficulty to isolate the product of reaction between $\mathrm{Ph}_{2} \mathrm{PCl}$ and $\mathrm{HNMeNH}_{2},{ }^{[4]}$ or the presence of two regioisomers in the reaction of $(\mathrm{PhO})_{2} \mathrm{P}(\mathrm{O}) \mathrm{Cl}$ with $\mathrm{HNMeNH}_{2}$, corresponding to the reaction of either the $\mathrm{HNMe}$ or the $\mathrm{NH}_{2}$ side of methylhydrazine.$^{[5]}$ The first successful use of methylhydrazine in phosphorus chemistry was proposed by one of us, with the synthesis of four phosphodihydrazide of type $\mathrm{RP}(\mathrm{X})\left(\mathrm{NMeNH}_{2}\right)_{2}$, with $\mathrm{R}=\mathrm{Ph}, \mathrm{NMe}_{2}$ for $\mathrm{X}=\mathrm{O}$, and $\mathrm{R}=\mathrm{PhO}, \mathrm{NMe}_{2}$ for $\mathrm{X}=\mathrm{S} .^{\left[{ }^{[6]}\right.}$ The inductive effect of the methyl group favors the reaction on the HNMe side. This work was developed towards the reaction

[a] Dr. J.-P. Majoral, Dr. A.-M. Caminade Laboratoire de Chimie de Coordination, CNRS

205, route de Narbonne, Toulouse 31077, Cedex 04, France E-mail: anne-marie.caminade@lcc-toulouse.fr

URL: https://www.Icc-toulouse.fr/article375.htm

[b] Dr. J.-P. Majoral, Dr. A.-M. Caminade

LCC-CNRS, Université de Toulouse, CNRS, Toulouse, France of methylhydrazine with $\mathrm{P}(\mathrm{S}) \mathrm{Cl}_{3}$. The 3 possible derivatives, corresponding to the reaction of 1,2 and 3 equivalents of methylhydrazine have been isolated, namely $\mathrm{Cl}_{2} \mathrm{P}(\mathrm{S}) \mathrm{NMeNH}_{2}$, $\mathrm{CIP}(\mathrm{S})\left(\mathrm{NMeNH}_{2}\right)_{2}$, and $(\mathrm{S}) \mathrm{P}\left(\mathrm{NMeNH}_{2}\right)_{3} .{ }^{[7]}$ It has been shown later by Infra-red studies that the lone pair of the nitrogen connected to phosphorus is partially delocalized towards phosphorus, inducing a weakening of the interaction of this lone pair with the $\mathrm{NH}_{2}$ group, in contrast with ordinary hydrazine derivatives. In consequence, the $\mathrm{NH}_{2}$ group has a comparatively higher basicity and nucleophilicity, which are comparable to that of amines. ${ }^{[8]}$ Such behavior was confirmed later by reaction of paraformaldehyde with a dihydrazide and a hexahydrazide (based on cyclotriphosphazene), affording stable methylene hydrazone units. ${ }^{[9]}$ Indeed, ab initio calculations have shown the electronic particularities of the (S)PNN=C linkage, in which the nitrogen linked to $\mathrm{P}$ is a weak $\mathrm{n}$-donor for the electron enrichment of the nitrogen carbon double bond. ${ }^{[10]}$

The work carried out in refs ${ }^{[6,7]}$ constitute the starting point for the synthesis of special phosphorus-containing architectures, namely macrocycles and dendrimers obtained by condensation reactions of phosphorhydrazides that will be displayed in this review.

Anne-Marie Caminade is Director of Research, Exceptional Class CNRS in Toulouse, and the head of the "Dendrimers and Heterochemistry" team. Her current research interest is on dendrimers and hyperbranched polymers, especially on phosphorus dendrimers, and on their uses. She is co-author of about 460 publications, 50 book chapters, 30 patents, editor of 2 books (h index 64 , over 13,500 citations).

Jean-Pierre Majoral is Emeritus Director of Research, Exceptional Class CNRS in Toulouse. His research interest is focused on phosphorus dendrimers and hyperbranched polymers, and on their uses. $\mathrm{He}$ is co-founder and scientific director of the start-up Dendris. He is a member of several Academies of Sciences, got a dozen of international awards, and is an author of over 650 publications, 7 books, 35 book chapters, and 45 patents (h index 65 , over 16,400 citations).
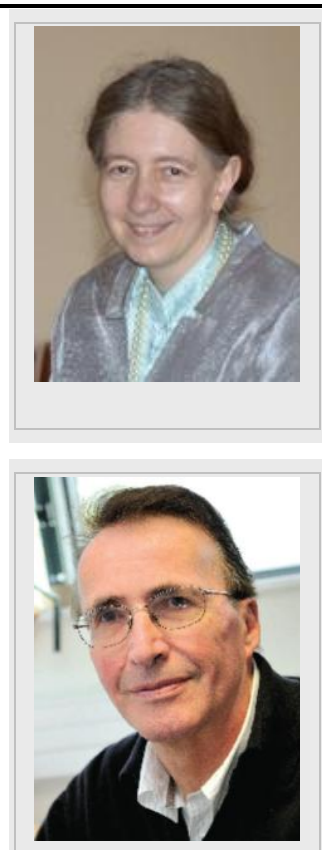


\section{Synthesis of phosphorhydrazone macrocycles and cryptands}

The discovery of crown ethers by C.J. Pedersen, ${ }^{[11]}$ has boosted the researches about macrocyclic compounds. However, the synthesis of large cycles is not easy, and many researches are still devoted to modified methods of synthesis, such as for instance diversity oriented macrocyclization strategy, termed multiple multicomponent macrocyclization including bifunctional building blocks. ${ }^{[12]}$ Macrobicycles, ${ }^{[13]}$ also named cryptands, ${ }^{[14]}$ are a special family of macrocycles. In this part of the review, we will show how phosphorhydrazide derivatives are powerful building blocks for the synthesis of phosphorus-containing macrocycles and cryptands.

The first series of phosphorhydrazone macrocycles was obtained by condensation reactions between phosphodihydrazides $\mathrm{RP}(\mathrm{X})\left(\mathrm{NMeNH}_{2}\right)_{2}$, with $\mathrm{R}=\mathrm{Ph}, \mathrm{PhO}, \mathrm{NMe}_{2}$ for $X=O$, and $R=P h, P h O$, for $X=S$, and dialdehydes of furane, pyridine or benzene, as shown in Scheme 1. Only macrocycles issued from the condensation of two equivalents of phosphodihydrazides with 2 equivalents of dialdehydes could be obtained, and the reaction yields were very high (isolated yield up to $95 \%$ in some cases), without using any templating or high dilution strategies. This work was the first demonstration of the usefulness of the phosphorhydrazide linkages for the elaboration of complex molecular architectures. ${ }^{[15]}$

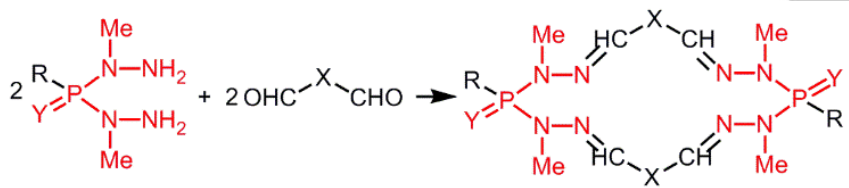

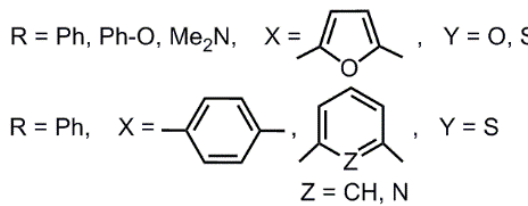

Scheme 1. The first macrocycles obtained by condensation of two equiv. of phosphodihydrazides with two equiv. of dialdehydes.

All the intermediates obtained during the reaction process were characterized by ${ }^{31} \mathrm{P} \mathrm{NMR}$, as shown in Scheme 2. Modifying the temperature $\left(-20^{\circ} \mathrm{C}\right)$ and the ratio between reagents helped to decipher this pathway, and some intermediates could be isolated. Single crystals of the corresponding final macrocycle permitted to confirm the macrocyclic structure, in the form of a butterfly when viewed from the P...P axis. The phosphoryl groups are in the cis position, and the nitrogen atoms in the $\beta$ position relative to the same phosphorus atom are at short distance. ${ }^{[16]}$

These macrocycles are stable but a few reactions have been attempted. The reduction of the hydrazones was very difficult, and could be observed only using a large excess of $\mathrm{LiAlH}_{4}$. In other experiments, methyltriflate was used to alkylate the sulphur of the $\mathrm{P}=\mathrm{S}$ groups, whereas trimethylsilyl triflate was used to silylate the oxygen of the $\mathrm{P}=\mathrm{O}$ groups. ${ }^{[17]}$

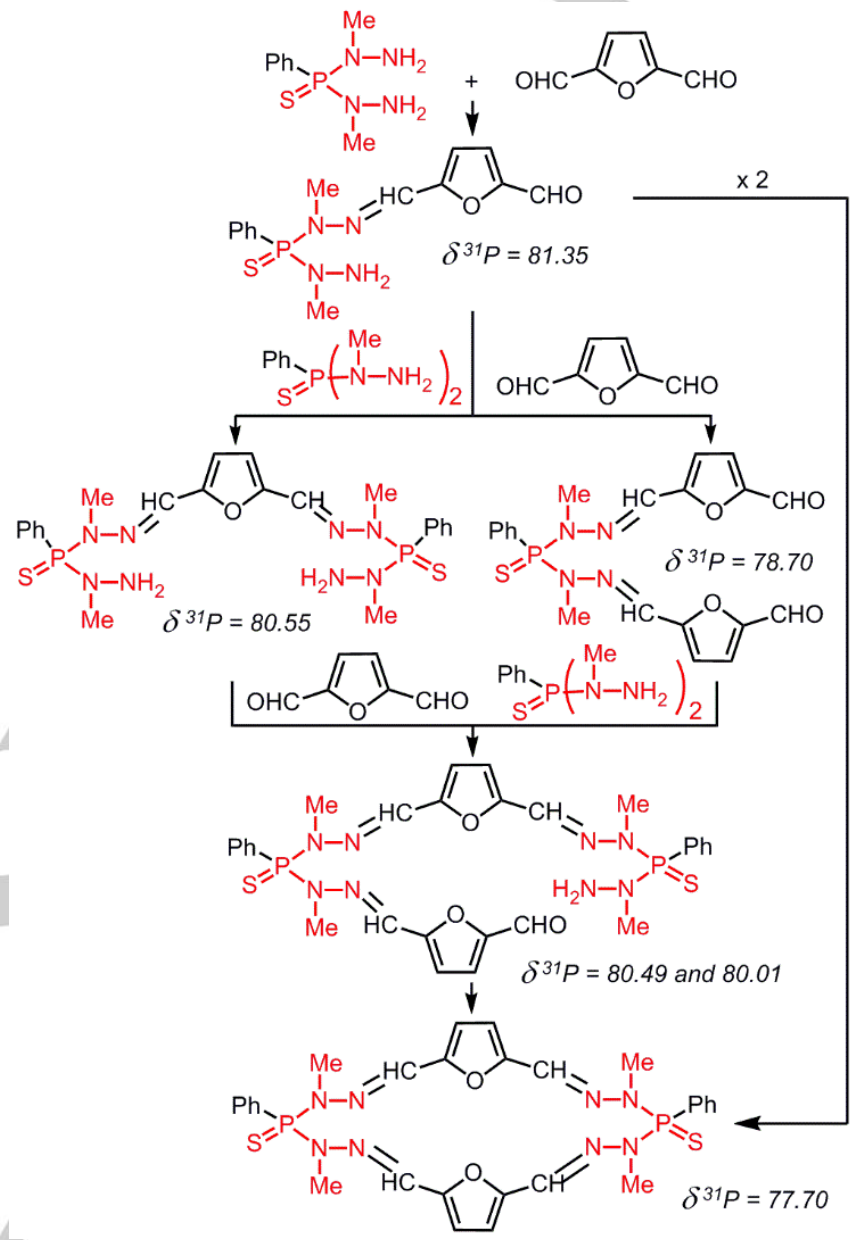

Scheme 2. Reaction pathway and ${ }^{31} \mathrm{P}$ NMR data for the synthesis of a macrocycle obtained by condensation of phosphodihydrazides with furane dialdehyde.

Many other types of dialdehydes have been used for the synthesis of phosphorhydrazone macrocycles. This includes a tetrathiafulvalene (TTF) derivative ${ }^{[18]}$ diverse phosphorylated diladehydes, ${ }^{[19]}$ and silane dialdehyde ${ }^{[20]}$ (Figure 1). 
<smiles>[Y][PH](c1ccccc1)(c1ccc(C=O)cc1)c1ccccc1C</smiles>

$\mathrm{Y}=\mathrm{O}$, lone pair<smiles>[R]POc1ccc(C=O)cc1</smiles>

$\mathrm{R}=\mathrm{Ph}, \mathrm{Me}_{2} \mathrm{~N}$

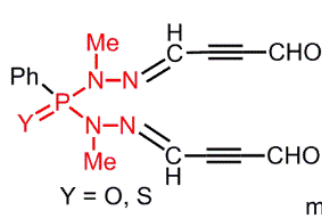

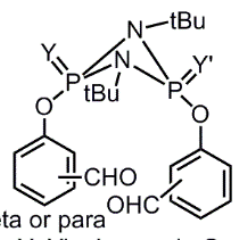

$\mathrm{Y}, \mathrm{Y}^{\prime}=$ lone pair, $\mathrm{S}$

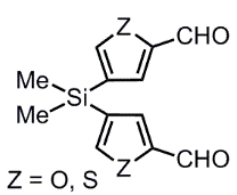

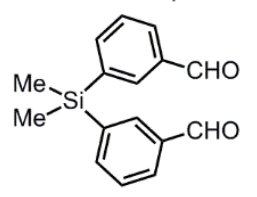

Figure 1. Other examples of dialdehydes used for the condensation with phosphodihydrazides as in Scheme 1.

Even if the condensation of two equivalents of each component is the most frequently observed reaction (noted $[2+2]),{ }^{[21]}$ the geometry of the dialdehyde influences the type of condensation. ${ }^{[22]}$ With a large dialdehyde, one equivalent of each component was sufficient to afford a macrocycle $([1+1]$ condensation), characterized by $\mathrm{X}$-ray diffraction, ${ }^{[23]}$ whereas with a short dialdehyde, a macrocycle issued from the reaction between 3 equivalents of phosphodihydrazide and 3 equivalents of pyrrole-2,5-dicarboxaldehyde ([3+3] condensation) and even 4 equivalents of each $\left([4+4]\right.$ condensation), was observed. ${ }^{[24]}$ Other examples of $[1+1],{ }^{[16,19 b, 22,25]}$ and $[3+3]^{[16,22,25]}$ cyclocondensation reactions have been published. Figure 2 displays the type of cyclocondensation reactions observed, in function of the size (number of bonds) of the macrocycle, together with the chemical structure of one of the smallest macrocycles $\left(18\right.$ bonds) issued from a $[1+1]^{[23]}$ cyclocondensation, and of the largest macrocycle (44 bonds), issued from a $[2+2]^{[22]}$ cyclocondensation.

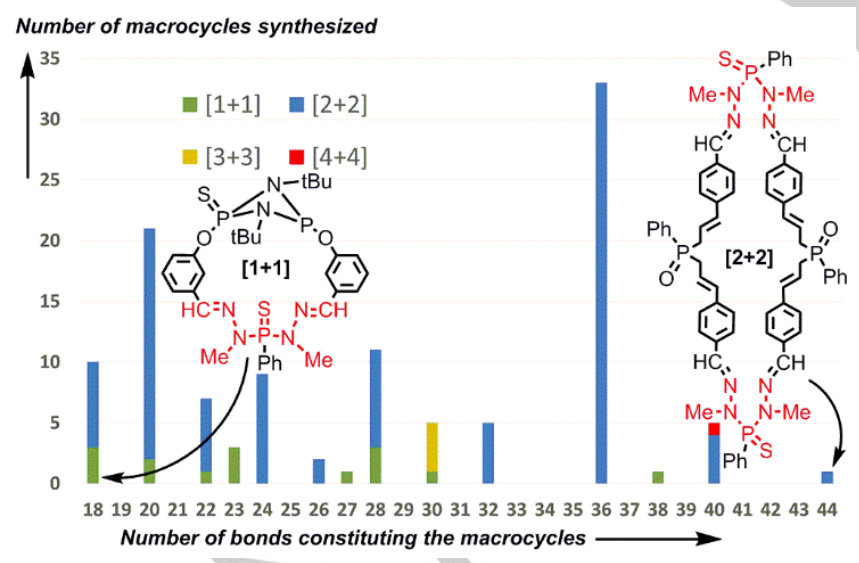

Figure 2. Types of condensations observed, depending on the size of the final macrocycle. The most frequently observed is the [2+2] condensation $(2$ equivalents of each reagent). Chemical structure of one of the smallest macrocycles, and of the largest one.
Another type of method has been used for the synthesis of phosphorhydrazone macrocycles, in which the first step is the condensation of a phosphodihydrazide with two equivalents of monoaldehydes bearing a phenol. Theses phenols were used in a second step for the substitution in basic conditions with $\mathrm{RP}(\mathrm{X}) \mathrm{Cl}_{2},{ }^{[26]} \mathrm{R}_{2} \mathrm{SiCl}_{2}$, or even metal dichlorides, ${ }^{[27]}$ in the presence of triethylamine (Scheme 3).

The macrocycles can be functionalized by either $\mathrm{Cl}$ or azide at the level of the phosphodihydrazides or of phosphorylated dialdehydes. ${ }^{[28]}$ The azide groups display a versatile reactivity towards phosphines as expected, but they also display a pseudo-halogen behaviour, ${ }^{[29]}$ which has led to the grafting of small dendrons. ${ }^{[30]}$ However, $\mathrm{N}_{3}$ has been used mainly for the synthesis of cryptands (macrobicycles), and also of a spherand. ${ }^{[31]}$ The first step is the synthesis of functionalized macrocycles, then the azides are used to react in Staudinger reactions with diverse diphosphines bridged by a long chain, which constitutes the third link of the cryptand (Scheme 4).

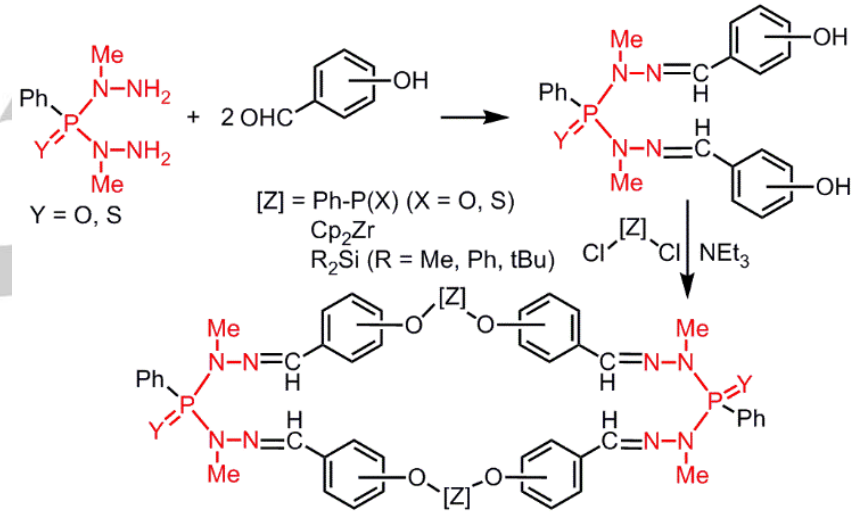

Scheme 3. Another type of method for the synthesis of phosphorhydrazone macrocycles. 

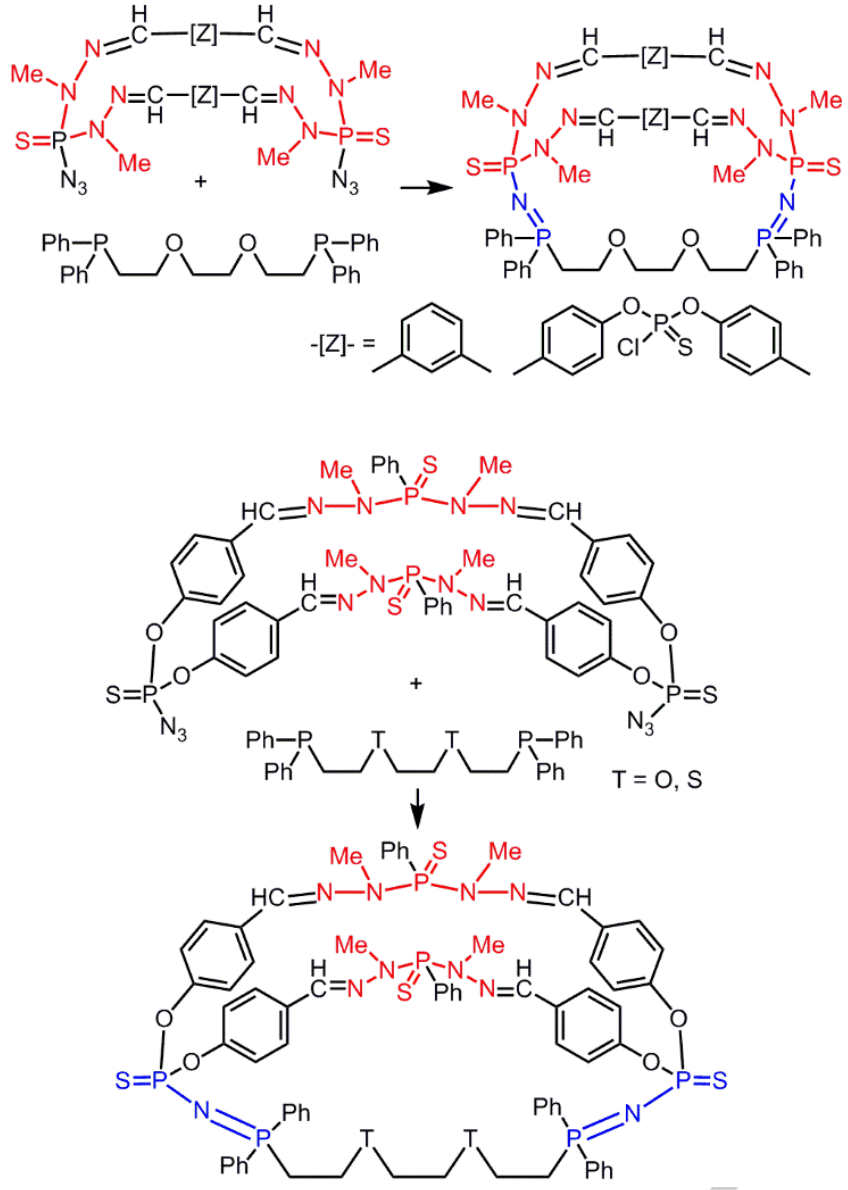

Scheme 4. Step-by-step synthesis of cryptands.

A macrocyclic diphosphine used in the same type of reaction with a macrocycle bearing two azides afforded the first example of a spherand based on phosphorus (Scheme 5). ${ }^{[31]}$

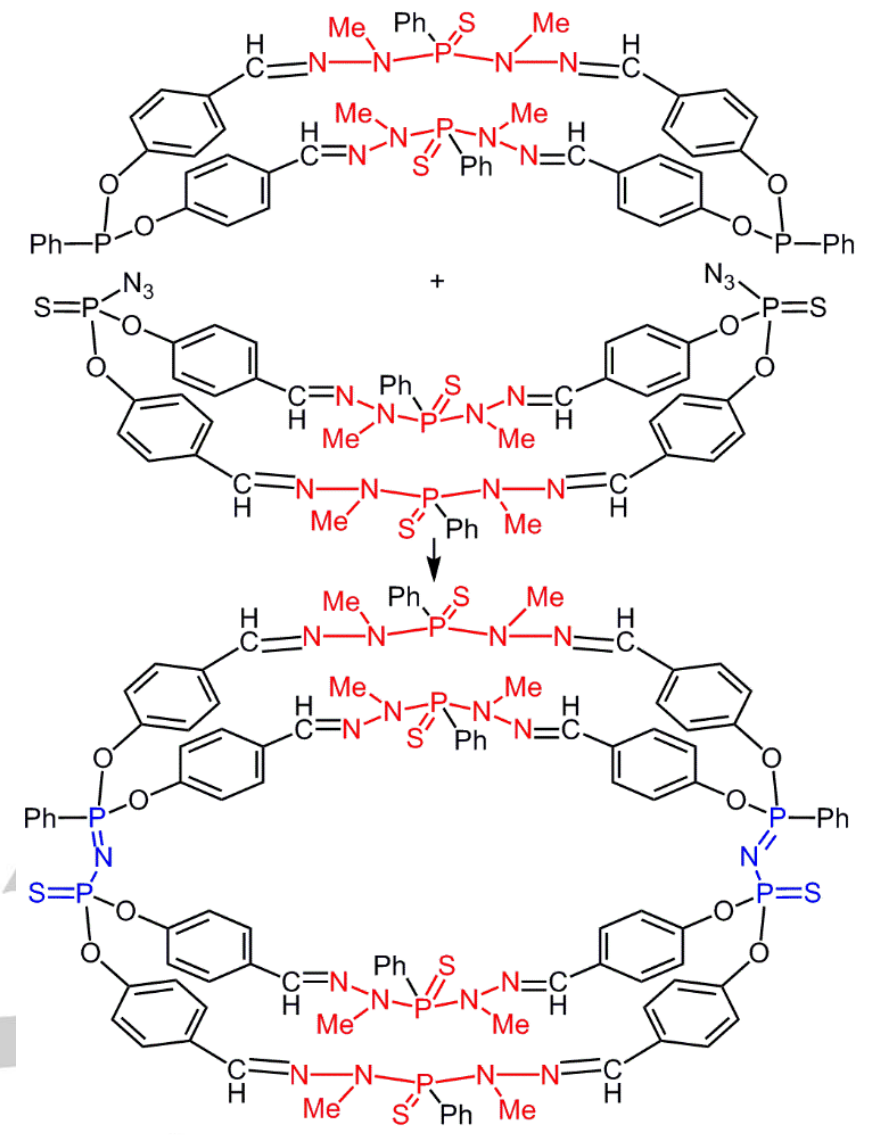

Scheme 5. First example of a spherand based on phosphorhydrazides.

The additional functions were also used for the synthesis of multimacrocyclic systems. ${ }^{[32]}$ Cryptands can be also obtained in a single step by the reaction of 2 equivalents of a phosphotrihydrazide with 3 equivalent of a dialdehyde (Scheme 6). ${ }^{[33]}$ This reaction is very sensitive to the geometry of the dialdehyde. Indeed, polymers constituted of associated macrocycles are obtained in most cases with this method instead of the expected cryptands. ${ }^{[34]}$

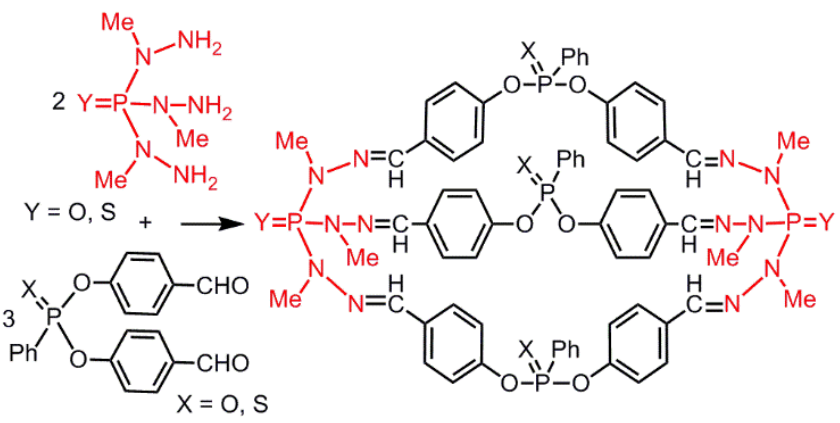

Scheme 6. Phosphotrihydrazides for the synthesis of cryptands and macrocyclic polymers. 
All this work demonstrates that the phosphorhydrazone linkage constitutes an excellent building block for the construction of special and sophisticated architectures such as macrocycles and cryptands. This method is by far the easiest and most powerful way to synthesize phosphorus-containing macrocycles. ${ }^{[35]}$ However, despite the presence of numerous heteroatoms, these macrocycles have relatively poor complexation ability. ${ }^{[21]}$ Besides macrocycles, the phosphorhydrazide linkage has been found also extremely useful for the synthesis of even more complex molecular architectures that are dendrimers and dendritic species, as will be emphasized in all the next paragraphs.

\section{Synthesis of phosphorhydrazone dendrimers and dendrons}

Dendrimers ${ }^{[36]}$ are macromolecules constituted of branched units radially arranged around a central core, whereas dendrons ${ }^{[37]}$ are dendritic wedges. Tens of thousands of publications concern dendrimers and dendrons, ${ }^{[38]}$ but only a few of them concern heteroatom-containing dendrimers. ${ }^{[39]}$ Over 450 publications, and two books (one in part, ${ }^{[40]}$ the other entirely ${ }^{[41]}$ ) concern dendrimers based on phosphorhydrazone linkages. We will give here an overview of the synthesis and the functionalization of these dendrimers.

The first publication, as most of the others, is based on the phosphorhydrazide $\mathrm{H}_{2} \mathrm{NNMeP}(\mathrm{S}) \mathrm{Cl}_{2}$. Even if $\mathrm{H}_{2} \mathrm{NNMeP}(\mathrm{O}) \mathrm{Cl}_{2}$ has been synthesized, the corresponding dendrimers ${ }^{[42]}$ are less stable than those obtained with the $\mathrm{P}(\mathrm{S})$ derivative. For the synthesis of dendrimers, the $\mathrm{NH}_{2}$ function is used in condensation reactions with aldehydes, and the $\mathrm{P}(\mathrm{S}) \mathrm{Cl}_{2}$ function in substitutions with phenols. The phosphorus atoms constitute the branching points in the structure of the phosphorhydrazone dendrimers. The first attempt was made from $\mathrm{P}(\mathrm{S}) \mathrm{Cl}_{3}$ used as core. The substitution and condensation reactions were used repeatedly to ensure the growing of the dendrimer. The number of terminal functions is doubled every two steps, and a new "generation" is created (Scheme 7). This work was first carried out up to the fourth generation, ${ }^{[43]}$ then the seventh generation, ${ }^{[4]}$ the tenth generation, ${ }^{[45]}$ and finally the twelfth generation, ${ }^{[46]}$ which has been the highest generation for any type of dendrimers for almost 20 years. In Scheme 7, the generation 1 is shown both as the full structure and in a linear form with parenthesis after each level of branching points. Generation 2 is shown only in the linear form; the number of terminal functions is obtained by multiplying all the numbers after the parentheses. In almost all the following Schemes and Figures, the structure of the dendrimers will be written in the linear form.

Different types of cores have been used for the synthesis of phosphorhydazone dendrimers. The most widely used is the cyclotriphosphazene $\mathrm{N}_{3} \mathrm{P}_{3} \mathrm{Cl}_{6},{ }^{[45,47]}$ which affords at each generation twice the number of terminal functions, compared to the $(\mathrm{S}) \mathrm{PCl}_{3}$ core. Furthermore, $\mathrm{N}_{3} \mathrm{P}_{3} \mathrm{Cl}_{6}$ offers the possibility to regio- and stereo-chemically control the nucleophilic substitutions, to have one (or several) function(s) different from the others. ${ }^{[48]}$

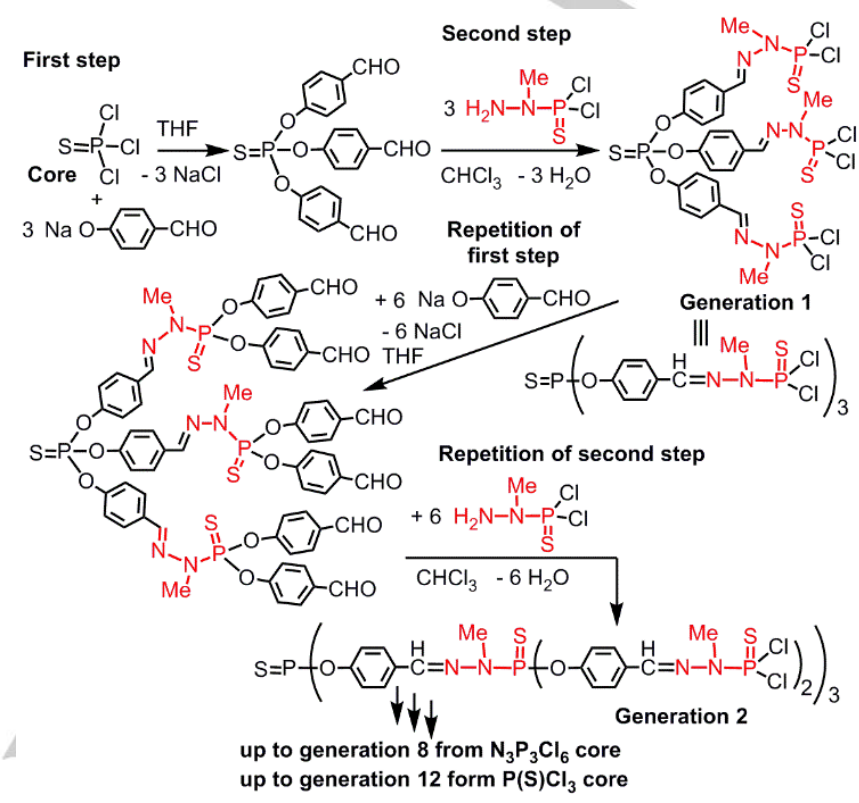

Scheme 7. Synthesis of phosphorhydrazone dendrimers from the $\mathrm{P}(\mathrm{S}) \mathrm{Cl}_{3}$ core. The first generation is represented both as a full chemical structure and in a linear form with parenthesis. This form is used also to represent generation 2.

Two ways are possible for obtaining functions in a $1 / 5$ ratio from the cyclotriphosphazene core: either grafting one function, then the other five (way A Scheme 8), or beginning by grafting five functions, then grafting the other one (way $B$, Scheme 8). These reactions have been applied to a lot of different compounds, as illustrated in Scheme 8. The $R_{1}$ and $R_{2}$ functions for way $A$ can be: $\mathrm{R}_{1}=$ pyrene, $\mathrm{R}_{2}=\mathrm{CHO}$ or $\mathrm{PPh}_{2} ;{ }^{[49]} \mathrm{R}_{1}=\mathrm{CO}_{2} \mathrm{Me}, \mathrm{R}_{2}=\mathrm{CHO}$; ${ }^{[50]} \mathrm{R}_{1}=\mathrm{CHO}, \mathrm{R}_{2}=$ maleimide; ${ }^{[51]} \mathrm{R}_{1}=\mathrm{Boc}$ or $\mathrm{CHO}, \mathrm{R}_{2}=$ dansyl or dabsyl derivatives; ${ }^{[52]} \mathrm{R}_{1}=\mathrm{NHBoc}, \mathrm{R}_{2}=\mathrm{CO}_{2} \mathrm{Me}$; ${ }^{[53]}$ or $\mathrm{R}_{1}=$ tyramineBoc, $\mathrm{R}_{2}=\mathrm{CHO} .^{[54]}$ Way $\mathrm{B}$ has been used less frequently, but it has been found useful in the following cases: $R_{1}$ $=\mathrm{NMeNH}_{2}, \mathrm{R}_{2}=\mathrm{PPh}_{2} ; \mathrm{R}_{1}=\mathrm{N}_{3}, \mathrm{R}_{2}=\mathrm{CHO} ;{ }^{[55]} \mathrm{R}_{1}=$ julolidine derivative, $\mathrm{R}_{2}=\mathrm{CHO} ;{ }^{[56]}$ or $\mathrm{R}_{1}=$ thioctic acid derivative, $\mathrm{R}_{2}=$ $\mathrm{CHO}^{[57]}$ In a few cases, two cyclotriphosphazenes have been associated with a short (double bonds, blue emitting) ${ }^{[58]}$ or long (triple bonds, green emitting) ${ }^{[59]}$ fluorescent compound bearing two identical functions (phenols), as shown in the bottom of Scheme 8.

Several other cores have been used for the synthesis of phosphorhydrazone dendrimers, bearing in particular aldehyde functions (Figure 3, left part). This family includes: a phthalocyanine bearing 8 aldehydes, ${ }^{[60]}$ an ammonium bearing 3 aldehydes, $^{[61]}$ a ferrocene ${ }^{[62]}$ and a pyridine ${ }^{[63]}$ bearing two aldehydes. Monoaldehydes bearing an alkyl chain, ${ }^{[64]}$ a methylester, ${ }^{[65]}$ or a polyethyleneglycol chain $(n=42)^{[66]}$ have been used for the synthesis of dendrons. Diverse types of 
phosphines have been used also as core, but the first step is the reaction with a phosphorus azide bearing two aldehydes, ${ }^{[31]}$ in Staudinger reactions (see the insert in Figure 3 ) to afford aldehyde functions. Several monophosphines have been used in this way for the synthesis of dendrons, starting from a triethoxysilylphosphine ${ }^{[67]}$ the vinylphosphine ${ }^{[68]}$ a phosphonatephosphine, ${ }^{[69]}$ and other types of monophosphines. ${ }^{[63]}$ A ferrocene bearing two phosphines, ${ }^{[70]}$ two diphenylphosphines bridged by an alkyl chain, ${ }^{[71]}$ and a triazatriolefinic macrocycle bearing 3 phosphines ${ }^{[72]}$ have been used as core of dendrimers (Figure 3). In all cases, the synthesis of the dendrimers/dendrons is carried out as shown in Scheme 7, starting from the aldehydes. Furthermore, the presence of a $\mathrm{P}=\mathrm{N}-\mathrm{P}=\mathrm{S}$ linkage at the core of dendrons induces an activation of the vinyl group, which displays a versatile reactivity with amines. $\left.{ }^{[73,74}\right]$
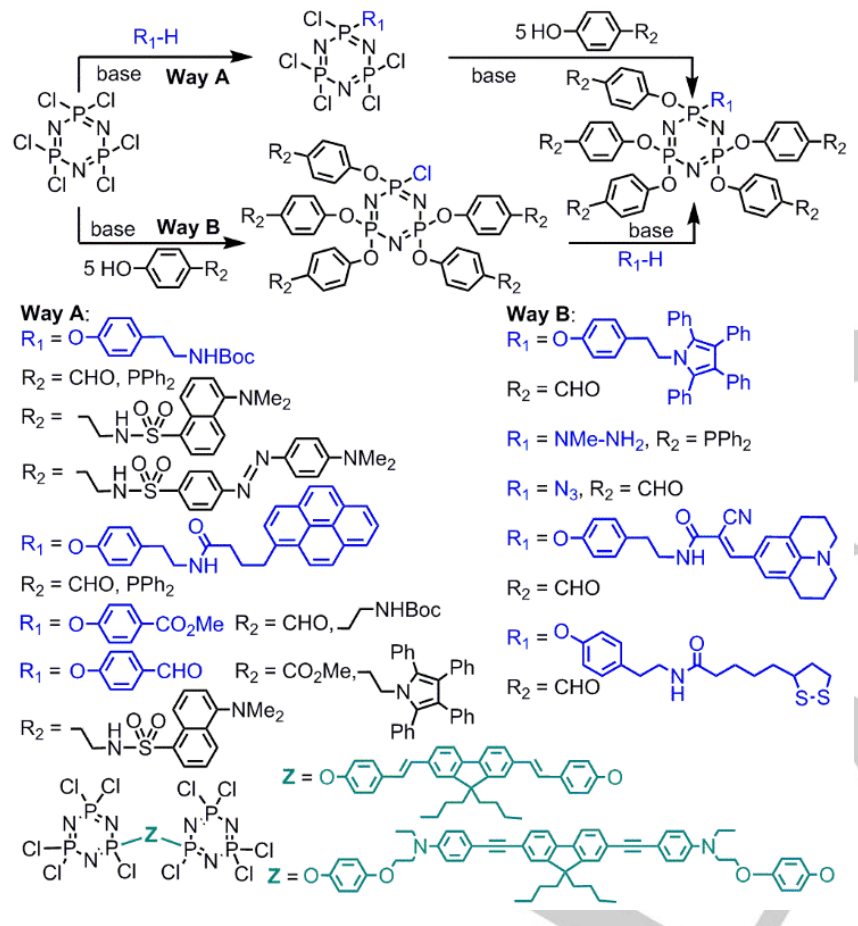

Scheme 8. Two ways for the functionalization of $\mathrm{N}_{3} \mathrm{P}_{3} \mathrm{Cl}_{6}$ with two functions in a $1 / 5$ or $5 / 1$ ratio. In the bottom, two cyclotriphosphazenes associated by fluorescent diphenols

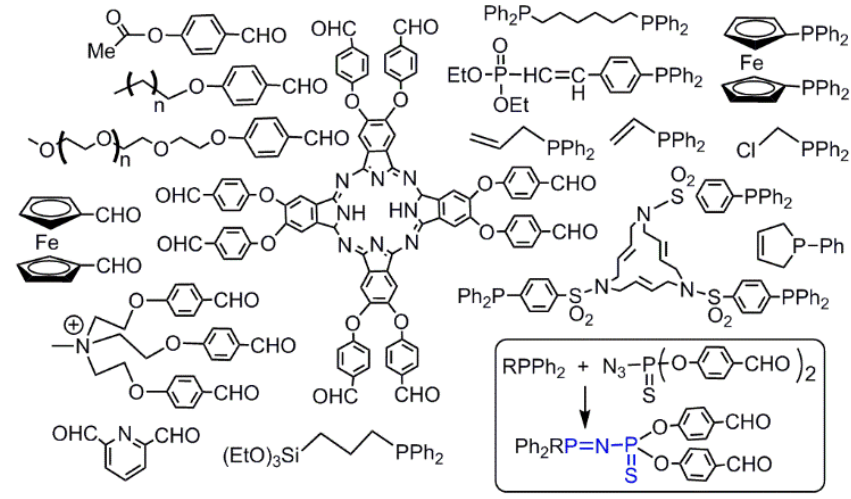

Figure 3. Other types of cores used for the synthesis of phosphorhydrazone dendrimers, functionalized either by aldehydes or phosphines. In the latter case, a Staudinger reaction with a dialdehyde azide is carried out to afford aldehyde functions (see insert) from which the synthesis of the dendrimers begins.

As shown in Scheme 7, the synthesis of phosphorhydrazone dendrimers necessitates the use of 4-hydroxybenzaldehyde in the branches. However, this compound can be replaced by other compounds possessing both a phenol and an aldehyde, to obtain modified branches in the dendritic structure. Several examples are given in Figure 4. They comprise several ferrocene derivatives, ${ }^{[62,75]}$ eventually chiral, ${ }^{[76]}$ slightly longer branches incorporating an alkene ${ }^{[77]}$ or another aryl group, ${ }^{[78]}$ or an azobenzene, ${ }^{[79]}$ green $^{[80]}$ and blue ${ }^{[81]}$ fluorene fluorophores, but also hydroxydialdehydes, either 5hydroxyisophthaldehyde, ${ }^{[82]}$ or another one based on triazine,${ }^{[83]}$ for multiplying more rapidly the number of terminal functions at each generation.

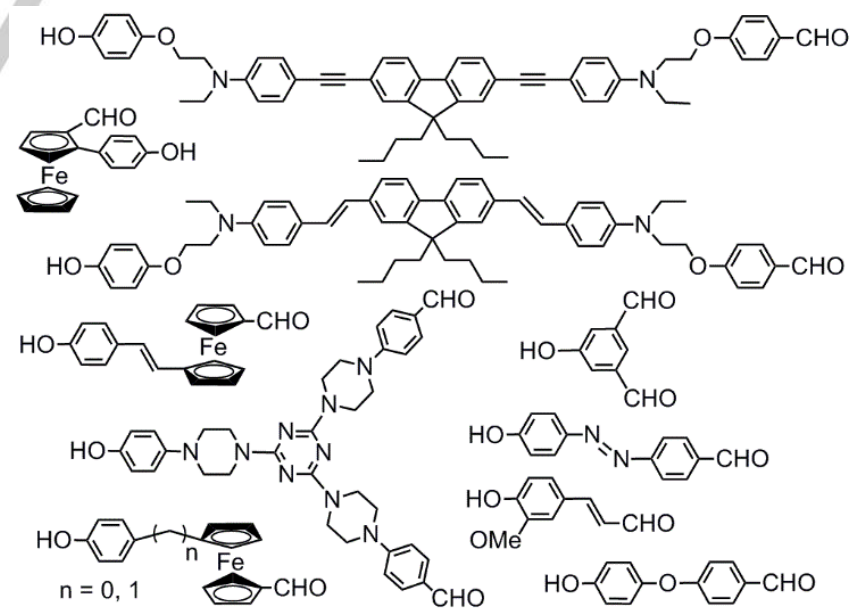

Figure 4. Examples of branches used instead of 4-hydroxybenzaldehyde for the synthesis of phosphorhydrazone dendrimers.

Besides changing the nature of the phenol-aldehyde, the synthesis of phosphorhydrazone dendrimers can accommodate 
different other methods, in particular those based on the Staudinger reaction, as shown for the cores in the insert of Figure 3 . Such reaction can be carried out at only a specific layer during the construction of the dendrimer, creating $\mathrm{P}=\mathrm{N}$ $\mathrm{P}=\mathrm{S}$ linkages only at this specific layer (see an example in Scheme 9). This linkage has a mesomeric form with a positive charge on the phosphorus of the $\mathrm{P}=\mathrm{N}$ group, and a negative charge on sulfur (see insert in Scheme 9). This form increases the reactivity of the sulfur atom compared to that included in the phosphorhydrazone linkage. For instance, it is possible to complex gold $(\mathrm{I})$ selectively on the $\mathrm{S}$ of the $\mathrm{P}=\mathrm{N}-\mathrm{P}=\mathrm{S}$ linkages,${ }^{[84]}$ but also to alkylate them specifically using methyltriflate ${ }^{[71]}$ (Scheme 9) or other alkyl triflates. ${ }^{\left[{ }^{[5]}\right.}$ Alkylation on sulfur induces a weakening of the $\mathrm{P}=\mathrm{S}$ bond, which can be cleaved easily and cleanly using a nucleophilic phosphine such as $\mathrm{P}\left(\mathrm{NMe}_{2}\right)_{3}$, to afford phosphines in the internal structure of the dendrimers. ${ }^{[86]}$ All the reaction steps can be monitored by ${ }^{31} \mathrm{P} N \mathrm{NMR}$, in particular on the $\mathrm{P}=\mathrm{S}$ group which gives a doublet at $52 \mathrm{ppm}$, then at 28 ppm after methylation of S, and $144 \mathrm{ppm}$ after desulfurization (Scheme 9). ${ }^{31} \mathrm{P}$ NMR is indeed a precious tool for the characterization of dendrimers. ${ }^{[87]}$ The tricoordinated phosphorus atoms inside the structure has been used for the complexation of gold, for alkylations with alkyl triflates, but mainly for Staudinger reactions with azides, allowing the internal functionalization with primary amines, isothiocyanates, ${ }^{[85]}$ pyrene derivatives, ${ }^{[88]}$ and aldehydes.
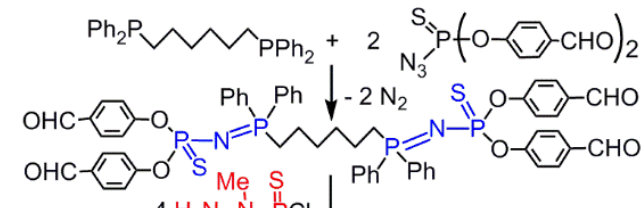
$4 \mathrm{H}_{2} \mathrm{~N}-\mathrm{N}-\mathrm{PCl}_{2} \downarrow$

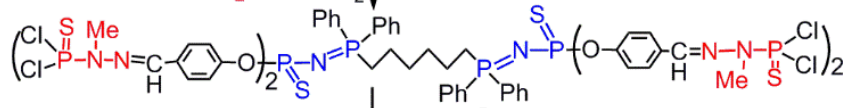
$8 \mathrm{NaO}-\mathrm{CHO}$

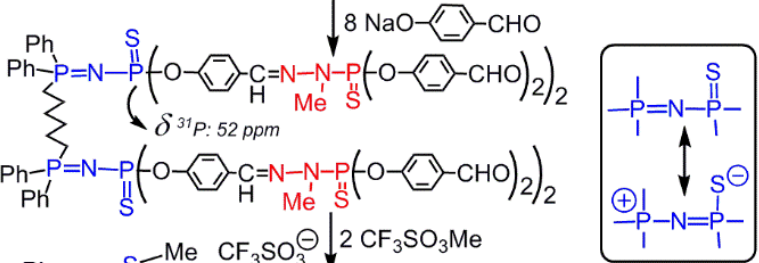

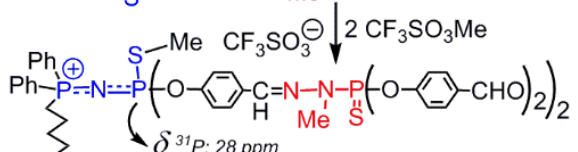

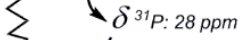<smiles>CSP(=S)(Oc1ccccc1)N(c1ccccc1)P(C)(=S)Oc1ccccc1</smiles>

Ph $\ldots \downarrow_{2} \mathrm{P}\left(\mathrm{NMe}_{2}\right)_{3}$

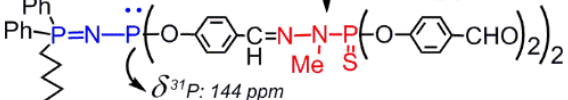

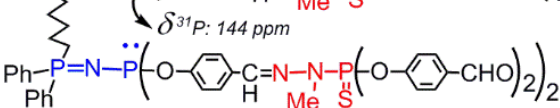

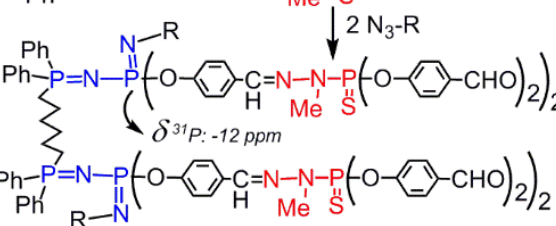

Scheme 9. Synthesis of phosphorhydrazone dendrimers incorporating $\mathrm{P}=\mathrm{N}$ $\mathrm{P}=\mathrm{S}$ linkages, and specific reactivity of this linkage for the internal functionalization of these dendrimers. ${ }^{31} \mathrm{P}$ NMR data to monitor the changes.

Several reactions have been carried out from internal aldehydes, ${ }^{[89]}$ but the most important is the growing of new branches inside the dendrimers built from a cyclotriphosphazene core and having $6 \mathrm{P}=\mathrm{N}-\mathrm{P}=\mathrm{N}-\mathrm{P}=\mathrm{S}$ groups. The two-step process shown in Scheme 7 has been applied 3 times to afford the first example in Figure 5 , but also a 3 -step process that creates $\mathrm{P}=\mathrm{N}-\mathrm{P}=\mathrm{S}$ linkages at each layer, as shown in the second example of Figure 5. These compounds are still amongst the most original examples of dendritic structures. ${ }^{[00]}$ Attempts to graft directly dendrons to the internal aldehydes inside the dendrimers was not possible for dendrons of the third generation, and very long for the second on (10 days). ${ }^{[7]}$ More details about these synthetic aspects can be found in two reviews. $\left.{ }^{[91,92}\right]$ Other special dendritic structures obtained through such types of reactions include layer block dendrimers, ${ }^{[68,74]}$ and Janus dendrimers. ${ }^{[53,93]}$ 


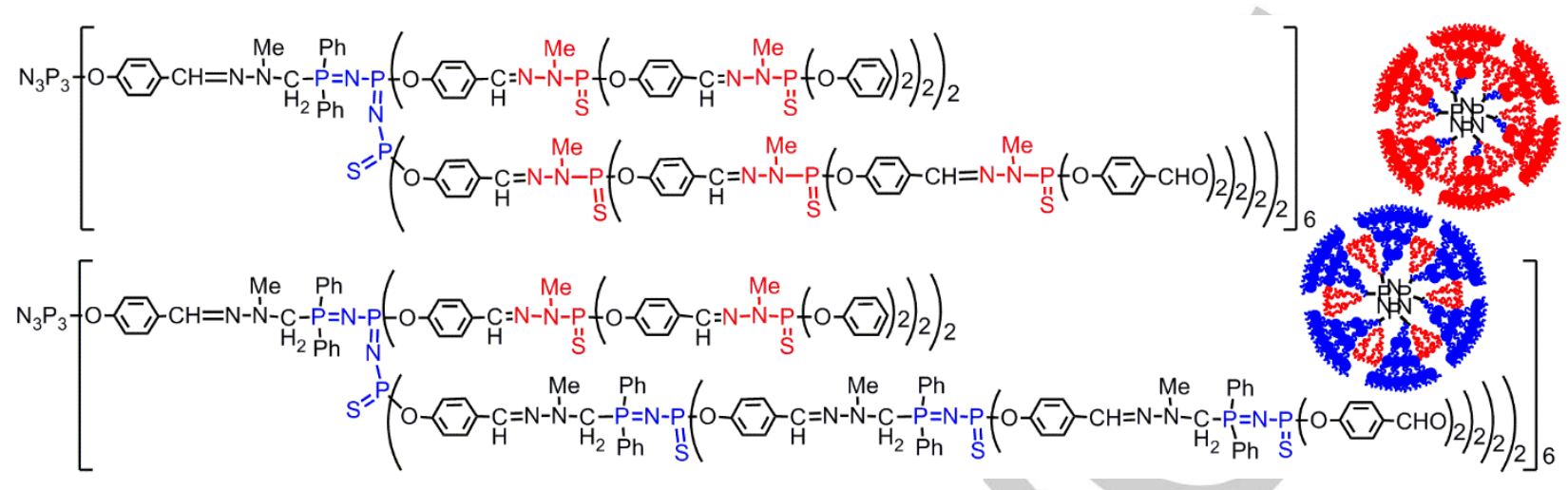

Figure 5. Result of the step-by-step synthesis of new branches within dendrimers; chemical and schematized structures.

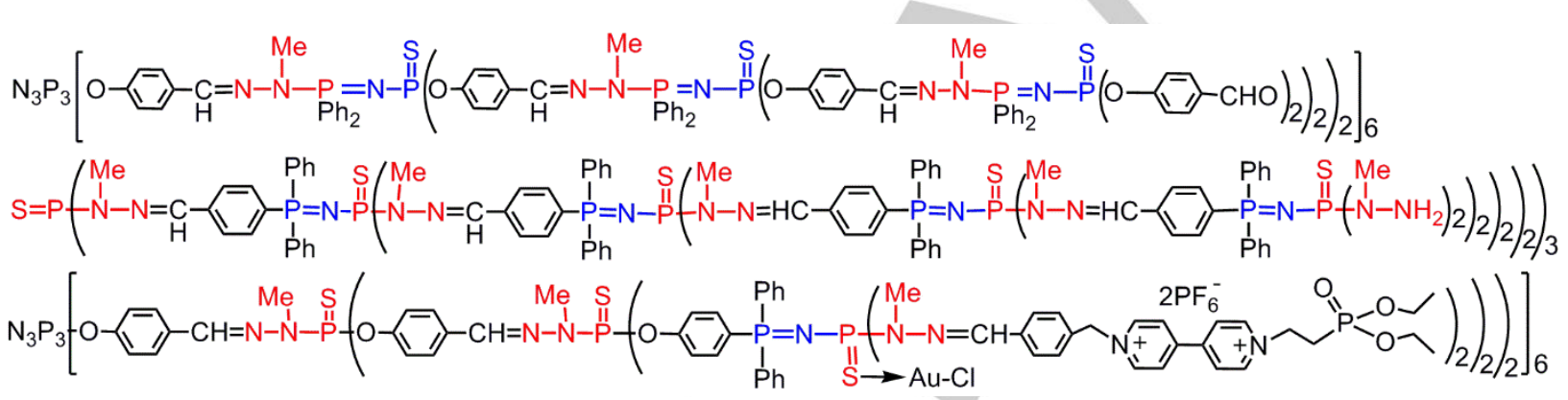

Figure 6. Examples of dendrimers in which phosphorhydrazone and $\mathrm{P}=\mathrm{N}-\mathrm{P}=\mathrm{S}$ linkages are closely associated, and of an "onion peel" dendrimer (bottom).

Other examples of dendrimers incorporating both phosphorhydrazone and $\mathrm{P}=\mathrm{N}-\mathrm{P}=\mathrm{S}$ linkages have been synthesized. In a first example, the synthesis necessitates three steps to build one generation, starting from aldehyde groups: i) condensation with methylhydrazine, ii) reaction with $\mathrm{Ph}_{2} \mathrm{PCl}$ in basic conditions, and iii) Staudinger reaction between the phosphine end groups and an azido dialdehyde, which affords again aldehydes as end groups. ${ }^{[94]}$ In a second example, a twostep process consists in condensation reactions between terminal $\mathrm{NH}_{2}$ groups issued from methylhydrazine and a monoaldehyde of triphenylphosphine. The second step is a Staudinger reaction between the phosphine and a phosphorus azide bearing two methylhydrazine ${ }^{[95]}$ Mixing several methods of synthesis can produce "onion-peel" dendrimers, ${ }^{[96]}$ in which each layer is different ${ }^{[97]}$ (Figure 6). Other examples concern accelerated methods of synthesis, in which the number of terminal functions is multiplied at each step, using two types of branched units bearing complementary functions, where $\mathbf{A}$ reacts only with $\mathbf{D}$, and $\mathbf{B}$ reacts only with $\mathbf{C}$. In view of our previous experiences, A should be $\mathrm{NH}_{2}, \mathbf{B} \mathrm{PPh}_{2}, \mathbf{C ~ N}$, and D $\mathrm{CHO}$, as shown in Figure 7. The first example concerned the use of $\mathbf{A B}_{2}$ and $\mathbf{C D}_{2}$ monomers, then $\mathbf{C A}_{2}$ and $\mathbf{B D}_{2}$ monomers, ${ }^{[98]}$ and finally $\mathbf{A B}_{2}+\mathbf{C D}_{5}, \mathbf{A B}_{5}+\mathbf{C D}_{2}$, and $\mathbf{A B}_{5}+\mathbf{C D}_{5}$ monomers, ${ }^{[55]}$ based on the cyclotriphosphazene, used as branching elements (Figure 7 ).
Recently, a new family of small dendrimers based on tri- or hexaphosphorhydrazide cores and repetitive viologen units was synthesized. ${ }^{[99]}$ One example is shown in Scheme 10. Other types of "onion peel" dendrimers have been synthesized by grafting carbosilane dendrons to phosphorhydrazone-viologen cores. ${ }^{[100]}$

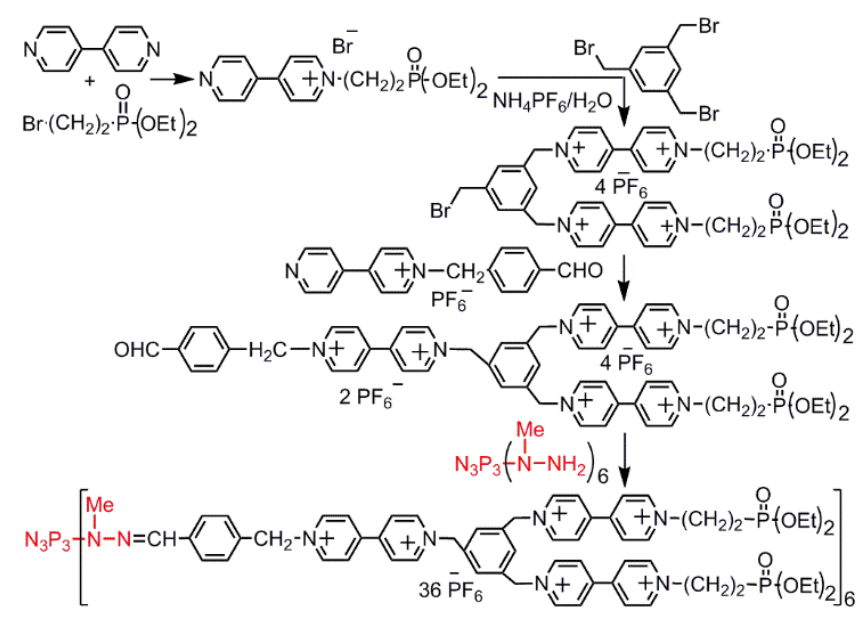

Scheme 10. One example of synthesis of viologen-phosphorhydrazone dendrimers. 

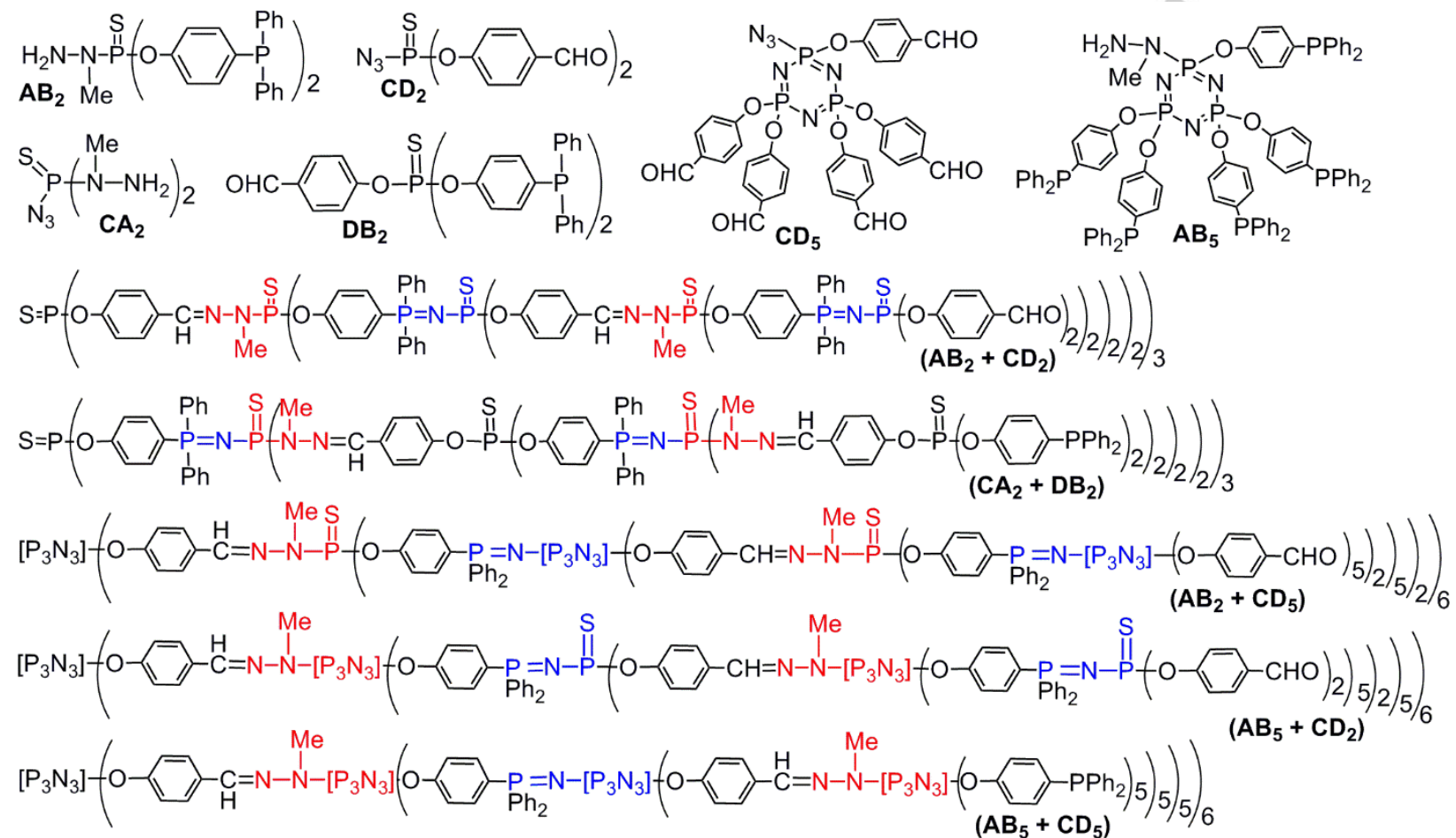

Figure 7. Results of accelerated methods of synthesis of phosphorhydrazone dendrimers, using two branched monomers.

The presence of either $\mathrm{CHO}$ or $\mathrm{P}(\mathrm{S}) \mathrm{Cl}_{2}$ terminal functions of phosphorhydrazone dendrimers, depending on the synthetic step considered, has enabled the grafting of a huge number of types of functions. From the aldehydes, many condensation reactions with functionalized hydrazines ${ }^{[101,102]}$ and amines ${ }^{[103,104]}$ have been carried out. Reductions have been carried out, either on the aldehydes, affording benzylalcohols, ${ }^{[105,106]}$ or on the imines affording amines. ${ }^{[107,108]}$ Additions of compounds having a $\mathrm{P}-\mathrm{H}$ group have been also carried out on both aldehydes ${ }^{[51,109]}$ and imines. ${ }^{[110]}$ Wittig and related reactions, ${ }^{[44,111-113]}$ and Doebner-like ${ }^{[114,115]}$ procedures (to cinnamic acids), have been also performed on the aldehydes. All these reactions will not be described in details, as they do not concern the phosphorhydrazones, which are the topic of this review, thus only the reactions on the $\mathrm{P}(\mathrm{S}) \mathrm{Cl}_{2}$ groups will be detailed. Substitution reactions with phenols bearing another function are the most widely used on $\mathrm{P}(\mathrm{S}) \mathrm{Cl}_{2}$ terminal groups of phosphorhydrazone dendrimers. Different types of such functions can be seen in Figure 8; they will be indicated from up to bottom. They comprise several ferrocene derivatives functionalized in most cases with a phosphine ${ }^{[116]}$ eventually linked to the cyclopentadienyl ring through a spacer. ${ }^{[117]}$ Many functionalized phenols have been prepared from tyramine $;^{[50,53]}$ this includes functions having biological properties such as azabisphosphonic acid salts ${ }^{[78,118]}$ of different types, ${ }^{[110]}$ diverse amido phosphonates, ${ }^{[119]}$ azabis carboxylate and azabis sulfonate salts, ${ }^{[120]}$ several mannose derivatives, ${ }^{[121]}$ ethacrynic acid, ${ }^{[122]}$ diverse phosphines such as an azabisphosphine, ${ }^{[123]}$ a thiazolylphosphine, ${ }^{[124]}$ and an iminophosphine ${ }^{[54]}$ diverse fluorophores such as a maleimide, ${ }^{[125]}$ and a derivative of rhodamine. ${ }^{[126]}$ Other functionalized phenols comprise ligands for catalysis, such as phosphine, ${ }^{[67]}$ and diphosphine, ${ }^{[127]}$ iminophosphine,$^{[128]}$ aminophosphine, ${ }^{[108]}$ diketone ${ }^{[129]}$ pyridineimine,${ }^{[130]}$ terpyridine,${ }^{[131]}$ bisoxazoline, ${ }^{[132]}$ prolinol derivative,$^{[133]}$ and cinchonine ${ }^{[134]}$ diverse other compounds, such as aminophosphoniums, ${ }^{[135]}$, thioesters ${ }^{[136]}$ and thioamides, ${ }^{[137]}$ two types of ethacrynic derivatives, ${ }^{[122,138]}$ long chains of type alkyl or perfluoroalkyl, ${ }^{[139]}$ or PEG (polyethyleneglycol), ${ }^{[80]}$ and fluorescent groups based on stilbazole $^{[140]}$ or fluorene derivatives. ${ }^{[59,141]}$ Miscellaneous functions are nitrile and dimethylamino, ${ }^{[68]}$ or alkyne and azide, ${ }^{[142]}$ or D-xylose, ${ }^{[143]}$ or ammonium ${ }^{[144]}$ (Figure 8). Attempts to graft specifically two different phenols have been assayed, as shown by the reaction of a phenol ethacrynic derivative and hydroxybenzaldehyde or azabisphosphonate tyramine, but contrarily to amines (see below), the reaction is not totally specific. ${ }^{[138]}$

The $\mathrm{P}(\mathrm{S}) \mathrm{Cl}_{2}$ functions are also able to react with diverse functionalized primary amines (in some cases secondary amines), such as allyl and propargylamine, and imidazole, ${ }^{[112]}$ diamines such as diethylethylene diamine and its methyl salt, ${ }^{[145]}$ and diverse diamines issued from pyrrolidine, morpholine, methyl piperazine, or phenyl piperazine. ${ }^{[146]}$ After the grafting of allylamine, only one $\mathrm{NH}$ on each $\mathrm{P}(\mathrm{NHAllyl})_{2}$ terminal group is 
able to react with $\mathrm{Ph}_{2} \mathrm{PCH}_{2} \mathrm{OH}$, affording tetrafunctionalized terminal functions (two allyl, one $\mathrm{NH}$, one phosphine) ${ }^{[147]}$ The diamines have been used mainly to afford water soluble dendrimers after the protonation of the tertiary amines. ${ }^{[148]}$ Several types of macrocycles have been used to obtain heterocycles comprising one phosphorus and two nitrogen atoms in a five- or six-membered ring. The macrocycles used were 1,4,8,11-tetraazacyclotetradecane, 1,4,8,12tetraazacyclopentadecane, 1,4,8,11-tetraazacyclotetradecane5,7-dione ${ }^{[149]}$ and a tri-olefinic triazamacrocycle having a diamine pendant arm. ${ }^{[150]}$ The reaction of amines proceeds cleanly step-by-step, thus it is possible to isolate the dendrimers issued form the reaction of a single $\mathrm{Cl}$ on each $\mathrm{P}(\mathrm{S}) \mathrm{Cl}_{2}$ function. This concerns for instance diallyl amine,${ }^{[44]}$ monoallyamine and propargylamine, ${ }^{[111]}$ two pyrene derivatives, [151] Bocmonoprotected ethylene diamine and 3-(triethoxysilyl) propylamine ${ }^{[50]}$ The second $\mathrm{Cl}$ can react in the reaction with a second amine, differently functionalized ${ }^{[50,112]}$ (Figure 9).

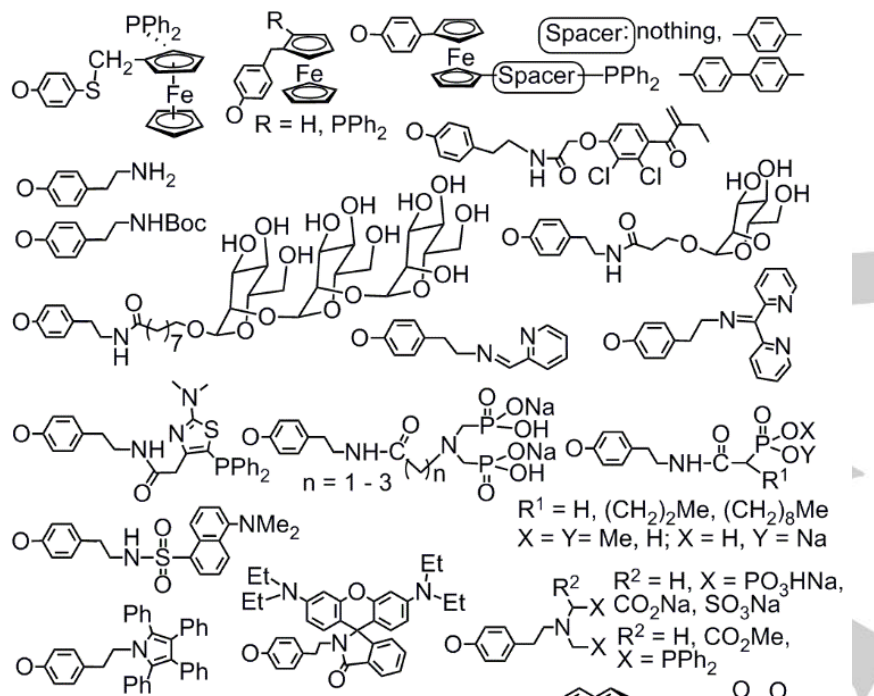

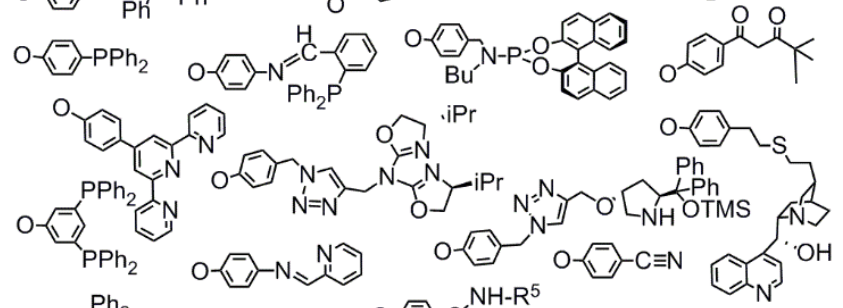
O- $-P_{\oplus}^{-\mathrm{N}_{2}}-\mathrm{R}^{3}$ O$\mathrm{R}^{3}=\mathrm{Et}, \equiv \mathrm{H} \quad \mathrm{O}-\mathrm{N}_{\mathrm{S}}^{\mathrm{S}} \mathrm{R}^{4}=\mathrm{Me}, \mathrm{CH}_{2} \mathrm{Ph}$<smiles>C#CCOc1ccc(Oc2ccc(/C=N/N(C)C(=O)OCc3ccc(Oc4ccccc4)c(Cl)c3)cc2)cc1</smiles>

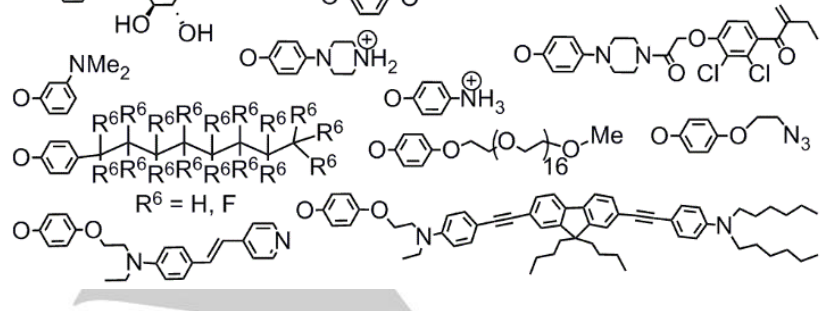

Figure 8. Examples of phenols grafted as terminal functions phosphorhydrazone dendrimers from the $\mathrm{P}(\mathrm{S}) \mathrm{Cl}_{2}$ functions.

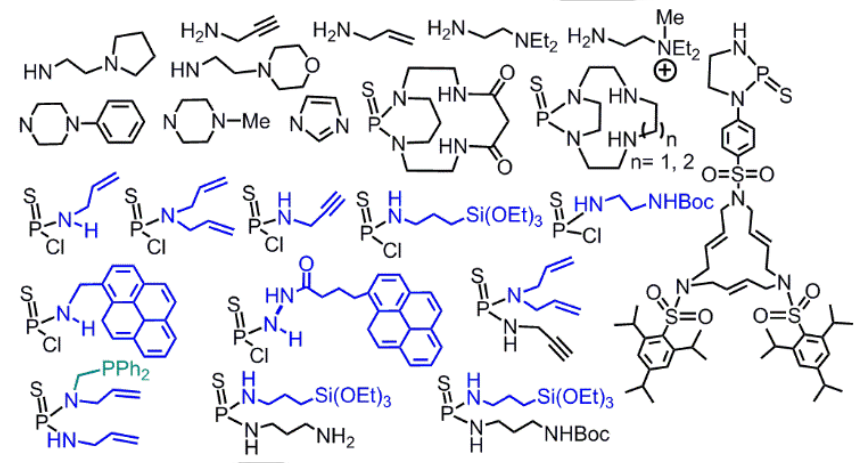

Figure 9. Examples of amines grafted as terminal functions of phosphorhydrazone dendrimers from the $\mathrm{P}(\mathrm{S}) \mathrm{Cl}_{2}$ functions. In the bottom, examples of grafting two different amines.

\section{Properties of phosphorhydrazone dendrimers}

Most of the properties of dendrimers depends on the nature of their terminal functions. Phosphorhydrazone dendrimers have been used in very different fields, ranging from catalysis ${ }^{[152]}$ to nanomaterials, ${ }^{[153]}$ fluorescence,${ }^{[154]}$ and biology/ nanomedicine. ${ }^{[155]}$ All these fields have been reviewed relatively recently, thus only selected examples will be given here.

\subsection{Catalysis with phosphorhydrazone dendrimers}

In the field of catalysis with phosphorhydrazone dendrimers, the main aims are to increase the efficiency, to reuse the catalysts, and to trigger the catalyst efficiency. The early experiments have been carried out with diverse phosphine complexes, ${ }^{[156]}$ then nitrogen ligands have been used too. ${ }^{[132]}$ In some cases, grafting a poorly efficient catalysts on the surface of the dendrimers can boost the efficiency, as illustrated in Figure 10 for copper complexes of pyridine-imines. The monomer (M) has practically no activity for the arylation of pyrazole with $\mathrm{Phl}$, whereas all the generations from $G_{1}$ to $G_{3}$ are very efficient (Figure 10 left). An increase of the efficiency when the generation increases has been observed when using $\mathrm{PhBr}$ instead of $\mathrm{Phl}$ (Figure 10 right). ${ }^{[130]}$ 


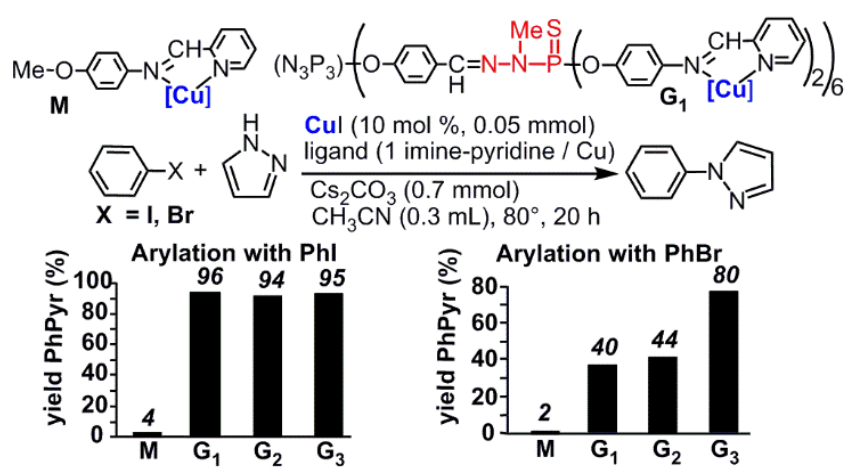

Figure 10. Copper catalyzed arylations. Comparison of the efficiency of a monomer and of generations 1-3 of the phosphorhydrazone dendrimers.

It must be noted that the quantity of copper is identical in all cases. For instance, 12 equiv. of the monomer are used to be compared with 1 equiv. of the first generation dendrimer, which possesses 12 complexes as terminal functions. The differences observed are an illustration of the so-called dendrimer (or dendritic) effect. ${ }^{[157]}$ In another example, the enantiodiscrimination has been largely increased for $[2+2+2]$ cycloaddition reactions catalyzed with dendritic phosphoramidite complexes of ruthenium; ${ }^{[108]}$ the corresponding monomeric complex induced no enantioselectivity.

The dendritic catalysts can be generally recovered by precipitation, as they are often less soluble than the reagents and products, and then, they can be re-used. The re-use has been carried out up to 12 times, with only a slight decrease in the efficiency on the twelfth run of Friedel-Crafts acylations using terpyridine lanthanide $\left(\mathrm{Sc}(\mathrm{OTf})_{3}\right)$ surface complexes of phosphorhydrazone dendrimers. ${ }^{[158]}$ To try to improve still the efficiency of the recovery, small dendrimers (generations 0 and 1) having a pyrene linked to the core, and phosphines suitable for the complexation of palladium as terminal groups were synthesized. The pyrene interacts by $\pi$-stacking with graphene layers covering magnetic cobalt nanoparticles. Desorption of the dendrimers from the surface of the nanoparticles was observed when heating the suspension to $60^{\circ} \mathrm{C}$, thus the catalysis can occur in homogeneous conditions. Desorption is reversible, and the dendrimers are again completely absorbed onto the nanoparticles on cooling. This assembly is very easily separated from the reaction media using a magnet, and re-used. This assembly has been assayed for catalysing Suzuki couplings, in particular for the synthesis of the anti-inflammatory drug Felbinac, obtained in quantitative yields from run 1 to Run 12 (Figure 11). ${ }^{[49]}$

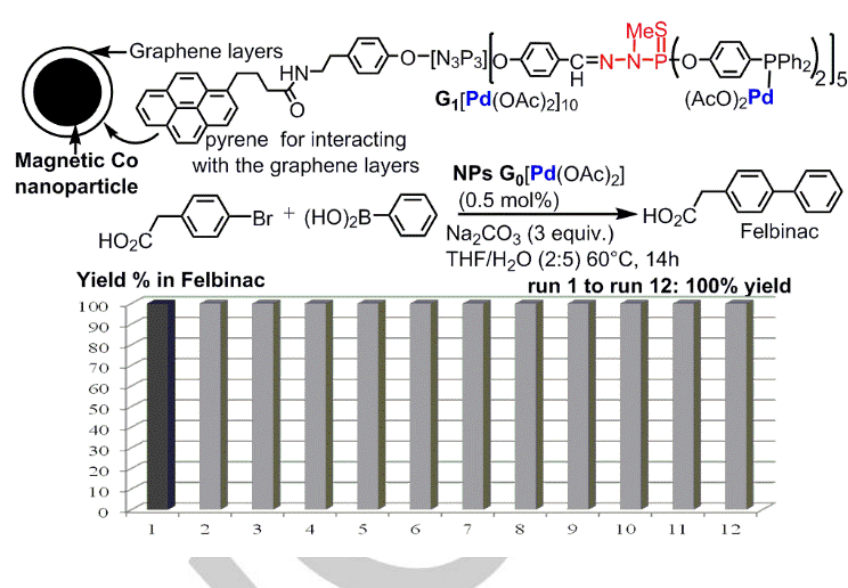

Figure 11. Non-covalent grafting of a dendritic catalyst onto magnetic cobalt nanoparticles, and their use for Suzuki couplings. Eleven recycling experiments carried out using a magnet for the synthesis of felbinac.

Catalyses in which oxidation and reduction both influence the electron-donating ability of a ligand and thus result in altered activity or selectivity of the catalyst are named RedoxSwitchable Catalyses (RSC). ${ }^{[159]}$ The very first example in the field of dendrimers concerned phosphorhydrazone dendrimers bearing as terminal functions ferrocenes (that will undergo the oxidation and reduction), functionalized with ruthenium $\mathrm{p}$ cymene complexes of phosphines. The first generation dendrimer was used as catalyst in the isomerization of allylic alcohols. In the oxidation step, addition of 1 equiv. of [ $\mathrm{Fe}\left\{\eta^{5}\right.$ $\left.\left.\mathrm{C}_{5} \mathrm{H}_{4} \mathrm{C}(\mathrm{O}) \mathrm{Me}\right\} \mathrm{Cp}\right]\left[\mathrm{BF}_{4}\right]$ per catalytic function induces a markedly reduced isomerization rate, due to the oxidation of the ferrocene (Figure 12). After reduction with $\left[\mathrm{FeCp}^{*}{ }_{2}\right]\left(\mathrm{Cp}^{*}=\mathrm{C}_{5} \mathrm{Me}_{5}\right)$, full conversion was observed, with an activity similar to that of the catalyst before oxidation. ${ }^{[117]}$

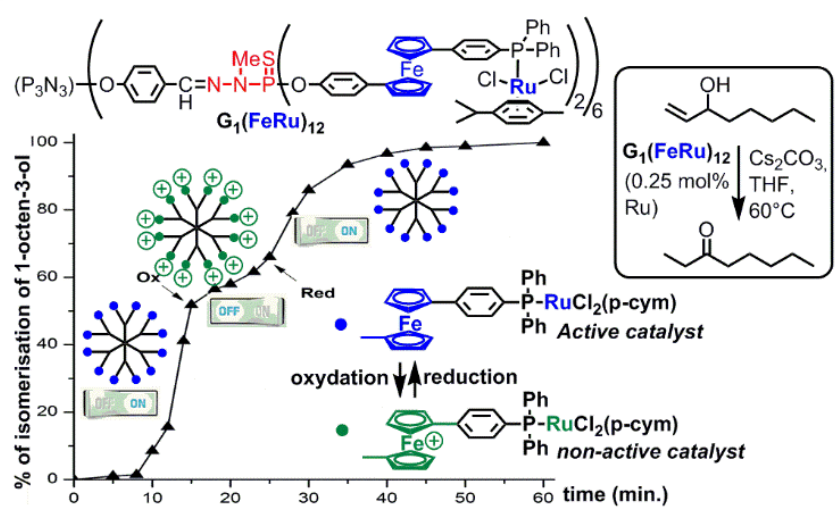

Figure 12. Switch ON/OFF/ON experiments carried out with a first generation dendrimer for the isomerization of 1-octen-3-ol into 3-octanone.

Besides organometallic catalysis in organic solvents, ${ }^{[160]}$ recent developments in the field of catalysis with dendrimers concern the use of water as reaction media, ${ }^{[106,124]}$ and organocatalysis, ${ }^{[161]}$ with phosphorhydrazone dendrimers 
decorated for instance with prolinol ${ }^{[133]}$ or cinchonine ${ }^{[134,162]}$ derivatives.

\subsection{Nanomaterials based on phosphorhydrazone dendrimers}

In the field of nanomaterials, ${ }^{[163]}$ three main domains have emerged concerning the use of phosphorhydrazone dendrimers, either the elaboration of materials incorporating dendrimers in their structure (hybrid materials), or materials exclusively composed of dendrimers, or the modification of the surface of materials, in particular towards sensors.

The first example of hybrid materials incorporating phosphorhydrazone dendritic structures concerned silica (Figure 13). Different types of dendrons having a triethoxysilyl group linked to the core, in combination with $\mathrm{Si}(\mathrm{OMe})_{4}$, used in hydrolysis condensation afforded silica xerogels, which were mesoporous in some cases. ${ }^{[67]}$ Other examples of incorporation of phosphorhydrazone dendrimers inside silica concerned dendrimers bearing ammonium terminal functions, which were used together with cationic surfactants and sodium silicate in water to elaborate periodic mesoporous silica of type MCM41. ${ }^{[164]}$ Recently, dendrimers and dendrons having in their structure triethoxysilyl groups were graft to nanoporous silica and used for the trapping of $\mathrm{CO}_{2} \cdot{ }^{[50]}$

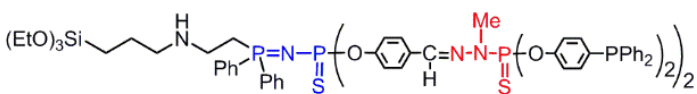

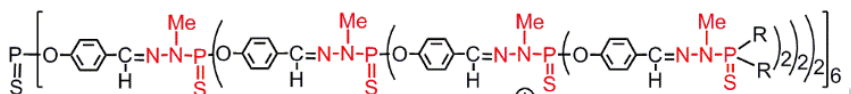

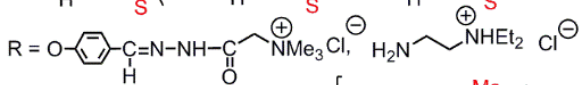

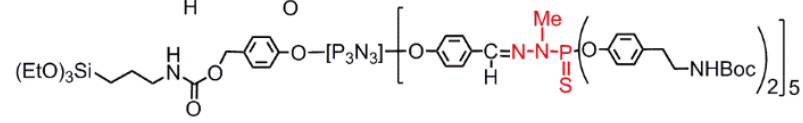

Figure 13. Examples of phosphorhydrazone dendrons and dendrimers used for obtaining hybrid silica.

Other inorganic materials incorporating phosphorhydrazone dendrimers (Figure 14) concerned first titanium oxo clusters $\mathrm{Ti}_{16} \mathrm{O}_{16}(\mathrm{OEt})_{32}$ bridged with small dendrimers functionalized with alcohols or carboxylic acids. ${ }^{[14]}$ Recently, generation 4 dendrimers with different terminal functions were used as mould for controlling the nucleation and growth of titanium-oxospecies. ${ }^{[165]}$ Unexpectedly, the dendritic medium provided at low temperature $\left(60^{\circ} \mathrm{C}\right)$ discrete anatase nanocrystals, and prevented up to $800^{\circ} \mathrm{C}$, the commonly observed anatase-torutile phase transformation. ${ }^{[166]}$ Positively charged small dendrimers were used for obtaining clay nanocomposites. Generation 2 afforded exfoliated clays, whereas generation 1 was incorporated inside clay, affording an expanded space between the layers, suitable for trapping pollutants such as chromate ions ${ }^{[167]}$ or methylene blue. ${ }^{[168]}$

$$
\begin{aligned}
& \text { SIO- }
\end{aligned}
$$

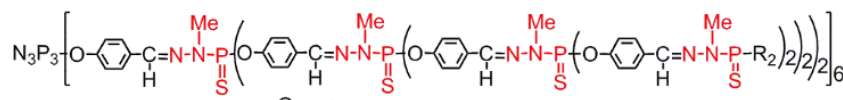

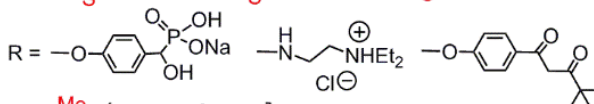

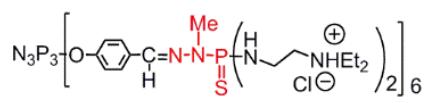

Figure 14. Examples of phosphorhydrazone dendrimers used for obtaining hybrid materials by reaction with metal alkoxides.

Other examples of hybrid materials concern metallic nanoparticles obtained thanks to phosphorhydrazone dendrimers (Figure 15). The first examples were based on dendrimers having thiol terminal functions which were able to peel the surface of gold clusters, to afford nanocrystals of naked $\mathrm{Au}_{55}$ protected by a shell of dendrimers. ${ }^{[102,169]}$ Triazatriolefinic macrocycles grafted as terminal functions were able to produce discrete nanoparticles of $\mathrm{Pd}$, usable as catalyst for Heck reactions. ${ }^{[170]}$ Even a single macrocycle at the core of phosphorhydrazone dendrimers having phosphine imines as terminal functions was able to produce $\mathrm{Pd}$ nanoparticles. ${ }^{[171]}$ Networks of Pt nanoparticles stabilized by the dendrimers having triazatriolefinic macrocycles terminal functions were also obtained. ${ }^{[150,172]}$ Ru nanoparticles were obtained by milling under air $\mathrm{RuCl}_{3}, \mathrm{NaBH}_{4}$ and phosphorhydrazone dendrons having an alkyl chain at the core and triarylphosphines as terminal functions. The resulting Ru nanoparticles were used as efficient catalyst for the hydrogenation of styrene. ${ }^{[64]}$ Phosphorhydrazone dendrimers grafted on silica nanoparticles, and bearing as surface functions phosphonates with lateral poly(ethyleneglycol) (PEG) chains have been used to host silver and silver oxide nanoparticles. The resulting nanocomposites exhibited antibacterial activity. ${ }^{[173]}$ 


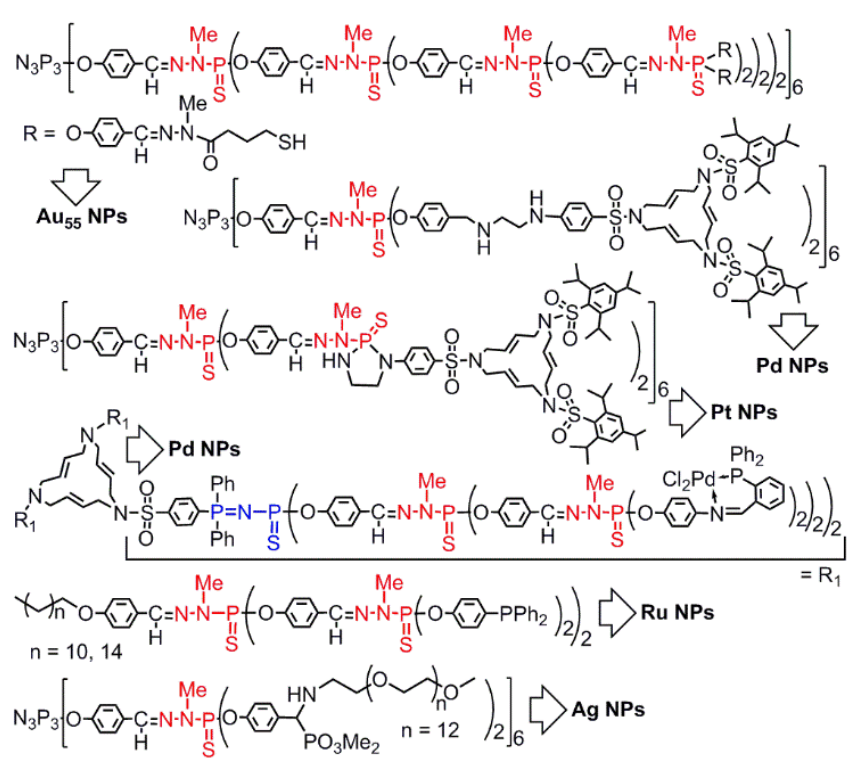

Figure 15. Examples of dendrimers and dendrons suitable for obtaining diverse types of metallic nanoparticles.

Some phosphorhydrazone dendrimers are materials by themselves. For instance, long alkyl chains $\left(C_{12}\right)$ linked to a triazatriolefinic macrocycle or to its open form, and grafted as terminal functions of phosphorhydrazone dendrimers from generation 0 to 4 display liquid crystal properties of type columnar, and mesomorphic properties over a wide temperature range ${ }^{[107]}$ Benzyl dithiobenzoate functions as terminal groups of a first generation dendrimer were used to afford hybrid star copolymers consisting of a dendritic core surrounded by polystyrene branches obtained by reversible additionfragmentation chain transfer (RAFT) (Figure 16). ${ }^{[136]}$ Star polymers based on phosphorhydrazone dendrimers were obtained by grafting poly(vinylidene fluoride) (PVDF) (Figure 16); an increased crystallinity of PVDF when grafted was observed. ${ }^{[174]}$ Three-dimensional polymers constituted of dendrimers as repeating units were obtained by hydrazine-toaldehyde Schiff-base formation (from aldehyde and hydrazine terminal functions of dendrimers) and amine-to carboxylic acid peptide-like coupling (from hydrazine and carboxylate terminal functions). ${ }^{[175]}$

Using the layer-by-layer (LbL) deposit of positively and negatively charged phosphorhydrazone dendrimers, different nano-objects have been obtained. When carried out in nanoporous alumina templates, this LbL process with 20 bilayers of dendrimers afforded after destruction of the template, nanotubes ${ }^{[176]}$ exclusively composed of positively and negatively charged dendrimers, for which the length $(80 \mu \mathrm{m})$ and the external diameter $(400 \mathrm{~nm})$ are those of the template. ${ }^{[177]}$ Some layers of negatively charged dendrimers have been replaced by negatively charged quantum dots. By choosing the order depending on the emission wavelengths of the quantum dots, graded bandgap architectures were obtained, suitable for detecting the hybridization of DNA inside the nanotubes. ${ }^{[178]}$ If using smaller pores for the template, the deposit of the dendrimers can be inhibited, even when the pores are by far larger than the dendrimers, due to electrostatic interactions, which are greater than on flat surfaces. ${ }^{[179]}$ The LBL experiments with dendrimers have been carried out also on nanoporous gold membranes. ${ }^{[180]}$ Microcapsules have been obtained by LBL deposit in alternation of dendrimers and polymers of opposite charges (poly(styrenesulfonate) (PSS) and positively charged dendrimer or poly(allylamine hydrochloride) (PAH) and negatively charged dendrimer) on the surface of melamine/formaldehyde microspheres. The microcapsules are obtained after destruction of the template microspheres. ${ }^{[181]}$ Stiffening of these capsules is observed when using THF. ${ }^{[182]}$ The microcapsules have been used for the encapsulation of small dye molecules. ${ }^{[183]}$ DNA has been used instead of PSS, with positively charged dendrimers, also for obtaining microcapsules. ${ }^{[184]}$

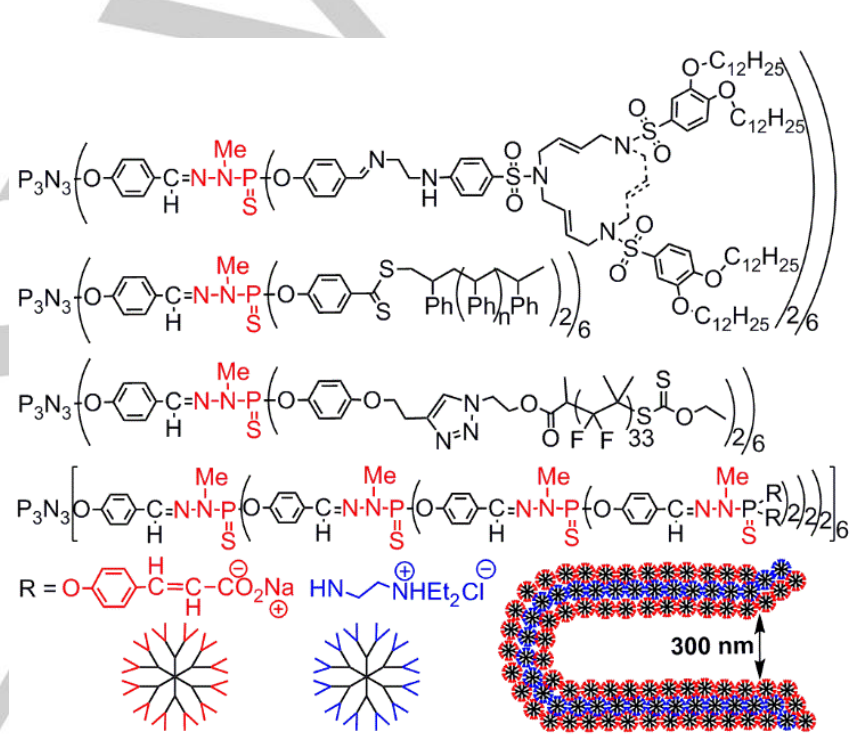

Figure 16. Examples of materials exclusively constituted of phosphorhydrazone dendrimers, from liquid crystals to star polymers, and to nanotubes.

Dendrimers deposited or covalently grafted to flat surfaces have been used in many cases as chemical sensors or as biological sensors. ${ }^{[185]}$ In the first case, thick layers of different generations (up to $\mathrm{G}_{9}$ ) of phosphorhydrazone dendrimers having aldehyde terminal functions were deposited on a quartz microbalance. Exposition of these layers to vapours of 30 organic solvents modified the quartz response, depending on the solvent and the generation of the dendrimers. A good correlation was observed between the solubility of dendrimers in a given solvent and their capacity to host vapours of this solvent. ${ }^{[186]}$ Another example concerned the LbL deposit of anionic gold nanoparticles and cationic phosphorus dendrimers also on a quartz crystal microbalance. After prolonged UV irradiation, the dendrimers were destroyed to afford only gold nanoparticles, which were used for the detection of several alcohols. ${ }^{[187]}$ TNT 
(trinitrotoluene) was detected by fluorescence quenching of thick layers of dendrimers having two-photon absorption properties. ${ }^{[188]}$ Other nitroaromatic compounds were detected by the quenching of fluorescence of a single layer of maleimide small bifunctional dendrimer grafted to titania thin films (Figure 17)..$^{[51]}$

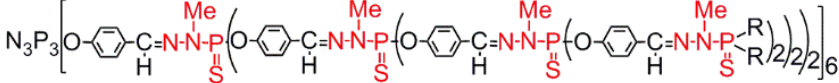

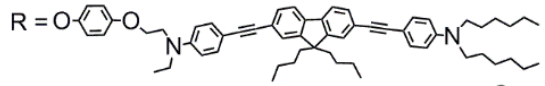

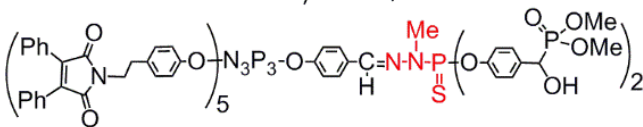

Figure 17. Examples of fluorescent phosphorhydrazone dendrimers used as sensors for nitroaromatic compounds.

However, the largest use of phosphorhydrazone dendrimers as sensors is for the detection of biological entities. The first example concerned dendrimers having aldehyde terminal functions, covalently grafted to quartz surfaces modified with aminopropyltriethoxysilane, which were used for the clustering of human serum albumin, as detected by AFM. ${ }^{[186]}$ The same dendrimers grafted to glass surfaces were then functionalized by a single stranded oligonucleotide, then this device was used as sensor for the detection of fluorescent complementary oligonucleotides. ${ }^{[190]}$ The best sensitivity was observed with generations 4 and 5 , which enable detection up to $10^{-12} \mathrm{M}^{[191]}$ (Figure 18). This method is very robust, and it has been used also for the detection of gold nanoparticles, ${ }^{[192]}$ of functionalized fluorescent liposomes, ${ }^{[193]}$ and for probing single molecule interaction by AFM. ${ }^{[194]}$ The robustness and sensitivity of these types of devices has led to the creation of a start-up (Dendris), in particular for the detection of respiratory pathogens. ${ }^{[195]}$

Other types of DNA sensors ${ }^{[196]}$ were obtained by grafting the probe DNA to the top layer of positively and negatively charged dendrimers deposited LbL. Detection of DNA hybridization was also detected by fluorescence, with a sensitivity of $3010^{-12} \mathrm{M}^{[197]}$ A largely improved sensitivity was obtained when using only two layers on $35 \mathrm{~nm} \mathrm{Ag}$ film and $5 \mathrm{~nm}$ Au film evaporated onto a glass substrate. One layer was constituted of a negatively charged perylene diimide labelled star polymer, and the other of a positively charged phosphorhydrazone dendrimer, to which the probe DNA was attached. Detection of hybridization was done using Surface Plasmon Enhanced Fluorescence Spectroscopy (SPFS) technique. The very high sensitivity of this method permit the detection of hybridization up to $10^{-18} \mathrm{M}^{[198]}$ (Figure 18).

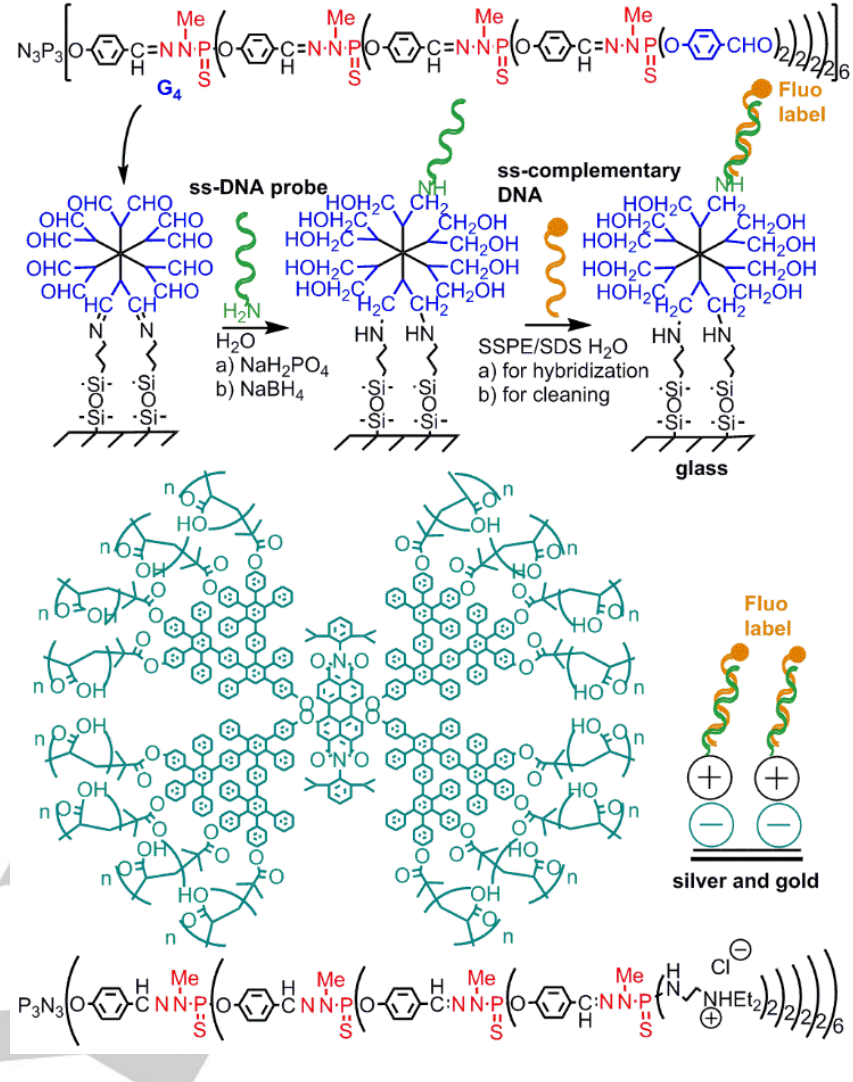

Figure 18. Examples of devices for the sensitive detection of DNA hybridization based on phosphorhydrazone dendrimers.

Phosphorhydrazone dendrimers bearing aldehyde terminal functions were also grafted to super-paramagnetic beads functionalized by $\mathrm{NH}_{2}$ groups. The beads were used for the capture of genomic DNA, and afforded better performances over the conventional method using streptavidin-coated magnetic beads. ${ }^{[199]}$ An analogous process was used for identifying lowabundance target nucleic acids in a complex matrix. ${ }^{[200]}$ The coated magnetic beads were also used for the selective removal of host nucleic acids, in view of increasing the detection sensitivity of low-abundance pathogenic species by PCR (polymerase chain reaction). ${ }^{[201}$ ]A recent sequel of this work consisted in the capture of RNA, to increase the detection sensitivity of bacterial or viral agents in complex host-pathogen mixtures. ${ }^{[202]}$

In between nanomaterials and biology, some phosphorhydrazone dendrimers have been used as supports for the culture of cells. Using the LbL method, foetal cortical rat neurons were cultured on the dendrimer films in order to investigate the influence of the surface charge of the outermost layer on their adhesion and maturation. In that case, it was shown that rat neurons attached preferentially and matured slightly faster on charged dendrimers. ${ }^{[203]}$ On the contrary, when using a single bifunctional dendrimer having one thioctic acid at the core to be covalently grafted to a thin layer of gold, human osteoblasts proliferated well on negatively charged dendrimers, 
whereas cell apoptosis was observed on positively charged dendrimers $^{[57]}$ (Figure 19).
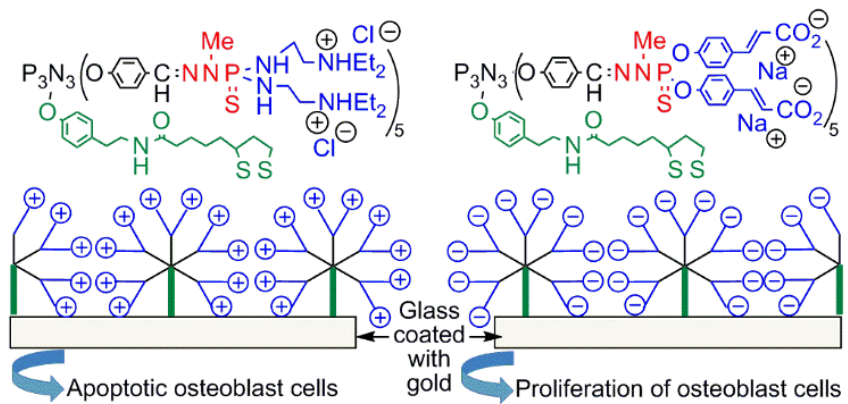

Figure 19. Examples of thin films of dendrimers used for the culture of cells.

\subsection{Fluorescent phosphorhydrazone dendrimers}

A few examples of fluorescent dendrimers have been displayed in the previous paragraphs (see in particular Figure 17), but many other examples of fluorescent phosphorhydrazone dendrimers have been synthesized. The fluorophores can be located at the core, or close to the core, in the branches, or most frequently as terminal functions, either on all of them, or on a few of them, in a stochastic way. Early attempts have been carried out for fundamental reasons, to detect for instance the presence of voids in the internal structure ${ }^{[88]}$ or the interaction between the terminal functions, ${ }^{[125]}$ and to propose an organic alternative to quantum dots, with the synthesis of dendrimers having two-photon absorption (TPA) properties. ${ }^{[141]}$ Attempts to produce blue Organic Light Emitting Diodes (OLEDs) with dendrimers having pyrene terminal functions have even been carried out. ${ }^{[204]}$ However, most of the work about fluorescent dendrimers has been carried out for biological purposes, for imaging and for deciphering mechanism of action of biologically active compounds.

A fluorophore having TPA properties and linked to two $\mathrm{N}_{3} \mathrm{P}_{3}$ functions (Scheme 8), from which dendritic branches surrounded by ammonium groups were built, was used for imaging in vivo the vessels of a rat olfactory bulb. ${ }^{[58]}$ A phthalocyanine used as core (see Figure 3 ) of positively charged dendrimers ${ }^{[60,205]}$ and a maleimide linked to the core ${ }^{[206]}$ were tentatively used to detect their penetration inside cells. A julolidine derivative linked to the core of negatively charged dendrimers was used to detect the penetration inside human monocytes ${ }^{[207]}$ (see Scheme 8). Fluorene derivatives constituting one layer (see Figure 4) of dendrimers having copper complexes as terminal functions were used to decipher the mechanism of the anti-cancer properties of these families of dendrimers. ${ }^{[81]}$ An azabisphosphonate dendrimer stochastically functionalized with fluorescein isothiocyanate (FITC) has been used to study its interaction with monocytes. ${ }^{[18]}$ A trimannoside dendrimer stochastically functionalized with julolidine has been used to study its interaction with the human DC-sign receptor. ${ }^{[121]}$
This fluorescence part is an introduction to the biology/nanomedicine part of this review, which will be organised depending on the charge of the terminal functions of the phosphorhydrazone dendrimers, ${ }^{[208]}$ in particular charged functions, which ensure the solubility in water. ${ }^{[209]}$

\subsection{Phosphorhydrazone dendrimers biology/nanomedicine}

in

Positively charged phosphorhydrazone dendrimers, in particular the fourth generation, which has been used for LbL deposit on various surfaces (see Figures 16 and 18), has also many biological properties. The full structure of the third generation of this family of compounds is shown in Figure 20 . The positively charged phosphorhydrazone dendrimers have been shown first to be efficient transfection agents to carry the plasmid of the luciferase inside mammalian cells. Generations 4 and 5 were the most efficient. ${ }^{[145]}$ Other transfection experiments concerned fluorescein-labelled oligodeoxyribonucleotide into HeLa cells, ${ }^{[205]}$ and the plasmid inducing an increased GDNF expression (the Glial cell line-Derived Neurotrophic Factor) into Schwann cells, isolated from sciatic nerves, in view of regenerating transected peripheral nerves in rats. ${ }^{[210]}$ The same dendrimer was used as carrier of a photosensitizer (rose Bengal) to enhance the photodynamic therapy efficiency, a cancer treatment alternative to chemotherapy and radiotherapy. ${ }^{[211]}$ Analogous experiments were carried out with a negatively charged phosphorhydrazone dendrimer and methylene blue. ${ }^{[212]}$ Phosphorhydrazone dendrimers bearing other types of ammonium terminal functions have been used to deliver single- and double-stranded DNA into cancerous cells, ${ }^{[146]}$ and to complex anti-TNF-alpha siRNA having anti-inflammatory properties. ${ }^{[213]}$ These nanocomplexes were administered intra-nasally in a murine acute lung injury model. ${ }^{[214]}$

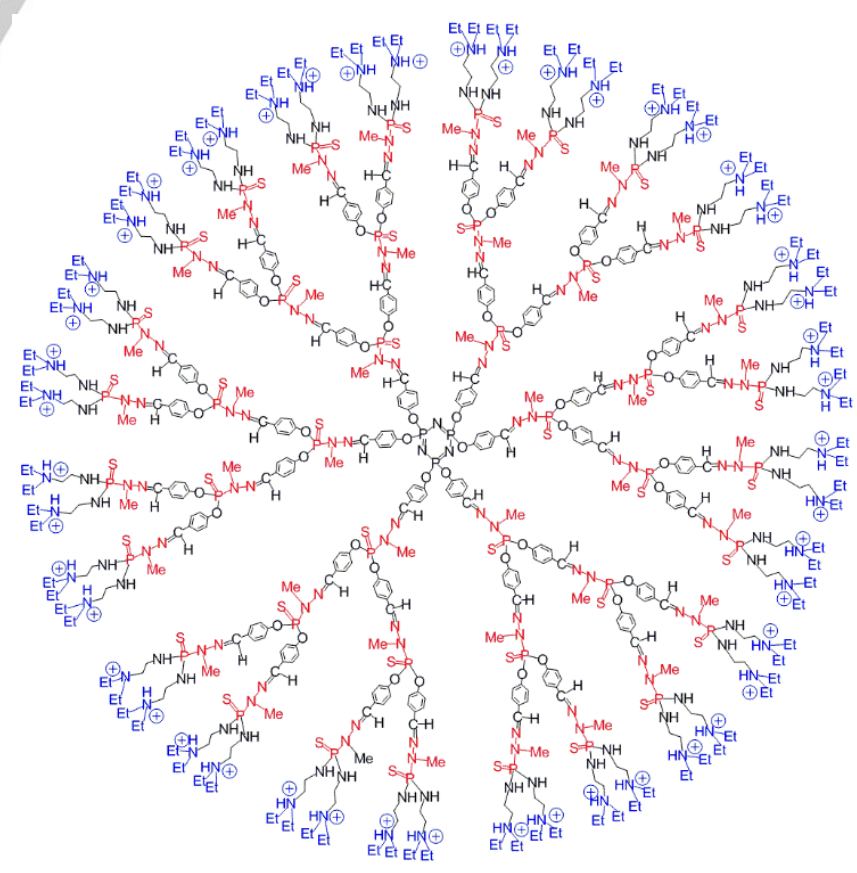


Figure 20. Full chemical structure of the generation 3 phosphorhydrazone dendrimer having 48 ammonium terminal functions.

These dendrimers have been used also against neurodegenerative diseases. They display a high anti-prion activity against the scrapie form of several strains of prions (PrP) which are responsible for several types of spongiform encephalopathies, such as Creutzfeldt-Jakob disease and mad cow disease, including in vivo. ${ }^{[215]}$ A sequel of this work concerned the interaction of dendrimers with the PrP 106-126 peptide ${ }^{[216]}$ which is suspected to be involved in the formation of amyloid fibrils in these encephalopathies, as well as the $A \beta 1-28$ peptide for Alzheimer's disease. ${ }^{[217]}$ The interaction of the same family of dendrimers with heparin, which is involved in the process of fibril formation in the prion diseases, was also measured. ${ }^{[218]}$

The viologen phosphorhydrazone dendrimers are also positively charged dendrimers, but the charges are inside the structure, and not as terminal groups (see examples in Scheme 10). Some biological properties of these viologen phosphorhydrazone dendrimers have been tested. ${ }^{[99]}$ They display low cell toxicity, ${ }^{[219]}$ they inhibit the cholinesterase activity (potential agents against neurodegenerative diseases), ${ }^{[220]}$ and they can prevent rotenone induced cell damages. ${ }^{[221]}$

Neutral phosphorhydrazone dendrimers are generally not soluble directly in water, the only exception being the mannose capped dendrimers (an example in Figure 8), which are directly soluble in water, and which were even used in vivo as an efficient preventing agent against acute lung inflammation. ${ }^{[121]}$ In the other cases, the dendrimers are first dissolved in a small quantity of DMSO, then the solution is added to a large quantity of water, to have about $1 \%$ of DMSO in the final solution to be tested. This process has been applied for instance to high generation dendrimers $\left(\mathrm{G}_{3}, \mathrm{G}_{4}\right)$ with neutral azabisphosphonate terminal functions, which inhibit macrophage-mediated inflammation response in vitro and in vivo. ${ }^{[222]}$ This has been done also for dendrimers capped with different types of pyridine imine ligands and for their $\mathrm{Cu}$ and $\mathrm{Au}$ complexes, all tested against cancer cells. Among them, the third generation dendrimer capped with pyridineimine functions issued from tyramine has been found the most efficient, ${ }^{[23]}$ probably because it forms the most stable complex with copper, ${ }^{[224]}$ and for which the mechanism of action has been studied. ${ }^{[81]} \mathrm{A}$ systematic study has been carried out by varying the type and number of complexes, on the surface of the third generation dendrimer, by complexing not only $\mathrm{Cu}(\mathrm{II})$, but also $\mathrm{Au}(\mathrm{III})$, eventually with additional PEG units. Figure 21 illustrates the stochastic functionalization with 8 PEGs, 10 free ligands, 10 gold complexes, and 20 copper complexes on the surface of the third generation phosphorhydrazone dendrimer. The presence of gold, even in small amounts largely increased the anti-cancer efficiency. ${ }^{[225]}$

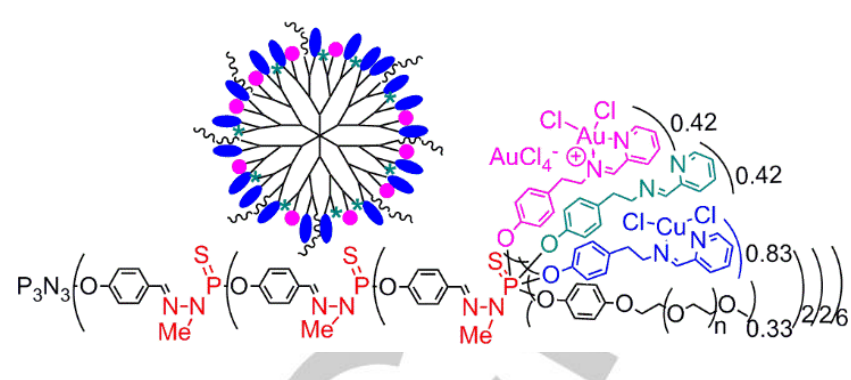

Figure 21. Stochastic functionalization of the third generation phosphorhydrazone dendrimer with 8 PEGs, 10 free ligands, 10 gold complexes, and 20 copper complexes.

Negatively charged phosphorhydrazone dendrimers have essentially either carboxylic acid or azabisphosphonate terminal functions. The carboxylic acid functions have been used for the protonation of amines of interest, affording electrostatic associations. This process has been first carried out with $\mathrm{N}$ hexadecylamino-1-deoxylactitol, ${ }^{[115]}$ (Figure 22) which is a chimera of galactosylceramide (galcer), a cellular receptor involved in the early stages of HIV infection. Analogous experiments were then carried out with dendrimers ended by different types of phosphonic acids ${ }^{[19]}$ instead of carboxylic acids, but the stability of the association in all cases is relatively low. ${ }^{[226]}$ The same concept has been applied to another phosphorus dendrimer, for the delivery of carteolol, which is an ocular antihypertensive drug against glaucoma (Figure 22). The efficiency of the delivery has been tested in vivo. ${ }^{[61]}$

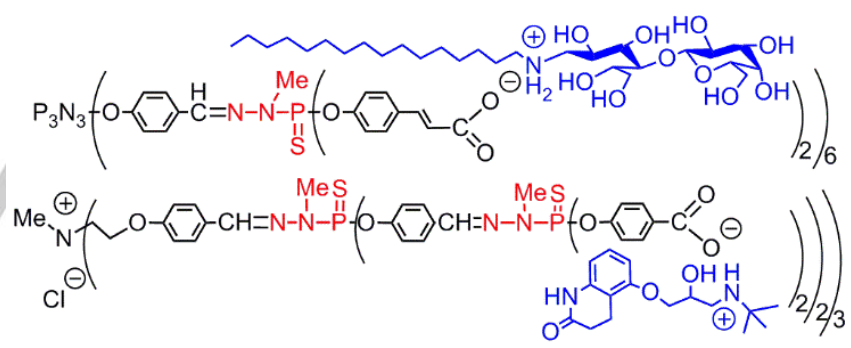

Figure 22. Electrostatic interaction between $\mathrm{N}$-hexadecylamino-1-deoxylactitol with a dendrimer bearing carboxylic acid terminal functions, and between cartéolol and another carboxylic acid dendrimer.

However, the most important negatively charged dendrimer is the first generation ended by 12 azabisphosphonic salt functions, for which the full structure (ABP) is shown in Figure 23. 


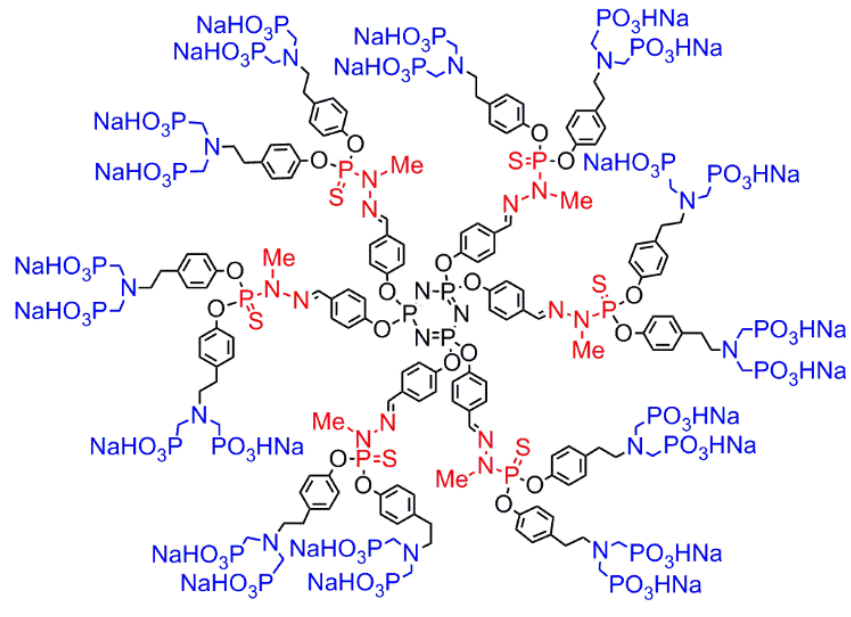

Figure 23. First generation of phosphorhydrazone dendrimer called ABP bearing azabisphosphonic acid salts as terminal functions.

This dendrimer $\mathrm{ABP}$ is able to penetrate in less than one minute inside monocytes, which are a key population of the human immunity in blood, and activate them, ${ }^{[18,227]}$ through an antiinflammatory pathway. ${ }^{[228]}$ The ABP dendrimer induces also a multiplication by several hundreds of the number of natural killer (NK) cells ${ }^{[110,229]}$ which are another key population of the innate immunity, in particular able to fight against cancers. A crosstalk between the activated monocytes and the NK cells is necessary to induce the multiplication of the NK cells. ${ }^{[230]}$ In view of these properties a large structure/activity study has been carried out, by varying many different parameters of the dendrimers structure, such as the number of terminal functions, ${ }^{[56]}$ their nature, ${ }^{[120,207]}$ but also the nature of the internal structure. Surprisingly, the most well-known dendrimers such as PAMAM, $\mathrm{PPI}$, and polylysine equipped with the azabisphosphonate terminal functions were non active, whereas all the dendrimers having phosphorus, or even silicon as branching points are efficient for the activation of monocytes. ${ }^{[78,231]}$ The antiinflammatory properties have led to use this dendrimer ABP in vivo against different diseases. The first assay concerned rheumatoid arthritis. The ABP dendrimer induces an antiosteoclastic activity in human cells, and inhibits the development of inflammatory arthritis in vivo in two mouse models. ABP was either injected (ip) or given orally (per os) with an almost analogous efficiency. ${ }^{[232]}$ In view of these very promising results, the dendrimer $\mathrm{ABP}$ was also tested in model of several inflammatory diseases, such as induced uveitis, ${ }^{[233]}$ and neuroinflammation, in mice suffering from a model disease of multiple sclerosis. ${ }^{[234]}$ In order to assess the preclinical safety of dendrimer $\mathrm{ABP}$, it was injected repetitively to monkeys, and no adverse effect was observed. ${ }^{[235]}$

\section{Conclusion}

Mono-, di-, and even tri- and hexa-phosphorhydrazide derivatives are indeed very powerful building blocks for the synthesis of special and aesthetic macromolecular architectures. In this Minireview, we have shown that the robustness and the reactivity of phosphorhydrazide derivatives has produced on one side large macrocycles and cryptands in high yields without using any templating strategy, and on the other side dendrimers, dendrons and very original dendritic architectures, in almost quantitative yields. All these families of macromolecules display also a versatile reactivity, in particular the dendrimers family, which has also afforded new properties and uses in different fields.

Indeed, highly efficient and re-usable catalysts, original nanomaterials, with improved sensitivity as biosensors, and above all, many biological properties have been implemented with phosphorhydrazone dendrimers. Furthermore, comparison of the properties of these dendrimers with that of other dendrimers have shown that these dendrimers are unique among others. ${ }^{[78]}$ This is certainly due to the presence of the phosphorhydrazone linkages, that induce an increased rigidity of the branches, as shown by X-ray crystal structures of small dendrimers ${ }^{[42,46,50,68,84,85]}$ which display flat arms for the $\mathrm{O}-\mathrm{C}_{6} \mathrm{H}_{4-}$ $\mathrm{CH}=\mathrm{N}-\mathrm{N}(\mathrm{Me}) \mathrm{P}(\mathrm{S})$ linkage. Such behavior undoubtedly increases the stability of the structures in which this linkage is incorporated. Thus we believe that the phosphorhydrazone linkages have not only a brilliant past, but also a bright future.

\section{Acknowledgements}

Thanks are due to the CNRS, to the ANR 2017 SLOW2 for financial support, and to the GDR Phosphore.

Keywords: macrocycle $\cdot$ dendrimer $\bullet$ phosphorhydrazone $•$ cryptand $\cdot$ phosphorus

[1] W. Steinkopf, Berichte der Deutschen Chemischen Gesellschaft 1908 , 41, 3571-3595.

[2] F. Ephraim, M. Sackheim, Berichte der Deutschen Chemischen Gesellschaft 1911, 44, 3416-3423.

[3] W. Strecker, H. Heuser, Berichte der Deutschen Chemischen Gesellschaft B 1924, 57B, 1364-1372.

[4] R. P. Nielsen, H. H. Sisler, Inorg. Chem. 1963, 2, 753-760.

[5] L. A. Cates, T. L. Lemke, J. Pharm. Sci. 1974, 63, 1736-1739.

[6] J. P. Majoral, R. Kraemer, J. Navech, F. Mathis, Tetrahedron Lett. 1975 1481-1484.

[7] J. P. Majoral, R. Kraemer, J. Navech, F. Mathis, J. Chem. Soc.-Perkin Trans. 1 1976, 2093-2098.

[8] R. Mathis, A. M. Pellizzari, T. Bouissou, M. Revel, M. Chihaoui, Spectrochim. Acta. 1981, 37A, 677-681.

[9] C. Galliot, A. M. Caminade, F. Dahan, J. P. Majoral, Angew. Chem. 1993, 105, 1508-1510; Angew. Chem.-Int. Edit. Engl. 1993, 32, $1477-$ 1479.

[10] C. Galliot, A. M. Caminade, F. Dahan, J. P. Majoral, W. Schoeller, Inorg. Chem. 1994, 33, 6351-6356.

[11] a) C. J. Pedersen, Science 1988, 241 (4865), 536-540; b) C. J. Pedersen, Anqew. Chem. Int. Ed. Enql. 1988, 27, 1021-1027.

[12] L. A. Wessjohann, D. G. Rivera, O. E. Vercillo, Chem. Rev. 2009, 109, 796-814.

[13] H. E. Simmons, C. H. Park, J. Am. Chem. Soc. 1968, 90, 2428-2429.

[14] B. Dietrich, J. M. Lehn, J. P. Sauvage, Chem. Comm. 1970, 1055-1056. 
[15] J. P. Majoral, M. Badri, A. M. Caminade, M. Delmas, A. Gaset, Inorg Chem. 1988, 27, 3873-3875.

[16] M. Badri, J. P. Majoral, A. M. Caminade, M. Delmas, A. Gaset, A. Gorgues, J. Jaud, J. Am. Chem. Soc. 1990, 112, 5618-5623.

[17] J. P. Majoral, M. Badri, A. M. Caminade, M. Delmas, A. Gaset, Inorg Chem. 1991, 30, 344-346.

[18] M. Badri, J. P. Majoral, F. Gonce, A. M. Caminade, M. Salle, A. Gorgues, Tetrahedron Lett. 1990, 31, 6343-6346.

[19] a) F. Gonce, A. M. Caminade, J. P. Majoral, Tetrahedron Lett. 1991, 32, 203-206; b) F. Gonce, A. M. Caminade, F. Boutonnet, J. P. Majoral, J. Org. Chem. 1992, 57, 970-975; c) D. Prevote, C. Galliot, A. M. Caminade, J. P. Majoral, Heteroat. Chem. 1995, 6, 313-318.

[20] N. Launay, F. Denat, A. M. Caminade, J. P. Majoral, J. Dubac, Bull. Soc. Chim. Fr. 1994, 131, 758-762.

[21] A. M. Caminade, R. Kraemer, J. P. Majoral, Inorg. Chim. Acta 1996, 246, 47-52.

[22] C. Galliot, A. M. Caminade, J. P. Majoral, M. Kuznikowski, M. Zablocka K. M. Pietrusiewicz, Chem. Ber. 1995, 128, 443-447.

[23] F. Gonce, A. M. Caminade, J. P. Majoral, J. Jaud, P. Vignaux, Bull. Soc Chim. Fr. 1992, 129, 237-241.

[24] B. Oussaid, B. Garrigues, J. Jaud, A. M. Caminade, J. P. Majoral, J. Org. Chem. 1993, 58, 4500-4503.

[25] J. P. Majoral, M. Badri, A. M. Caminade, Heteroatom Chem. 1991, 2 45-54.

[26] D. Colombo, A. M. Caminade, J. P. Majoral, Inorg. Chem. 1991, 30 3365-3367.

[27] N. Launay, F. Denat, A. M. Caminade, J. P. Majoral, J. Dubac, Bull. Soc. Chim. Fr. 1994, 131, 758-762.

[28] J. Mitjaville, A. M. Caminade, J. P. Majoral, Synthesis-Stuttgart 1995 952-956.

[29] a) G. Magro, A. M. Caminade, J. P. Majoral, Tetrahedron Lett. 2003, 44 7007-7010; b) E. K. Apartsin, A. G. Venyaminova, S. Mignani, A. M. Caminade, J. P. Majoral, New J. Chem. 2018, 42, 8985-8991.

[30] C. O. Turrin, A. Maraval, G. Magro, V. Maraval, A. M. Caminade, J. P. Majoral, Eur. J. Inorg. Chem. 2006, 2556-2560.

[31] J. Mitjaville, A. M. Caminade, R. Mathieu, J. P. Majoral, J. Am. Chem. Soc. 1994, 116, 5007-5008.

[32] J. Mitjaville, A. M. Caminade, J. C. Daran, B. Donnadieu, J. P. Majoral J. Am. Chem. Soc. 1995, 117, 1712-1721.

[33] J. Mitjaville, A. M. Caminade, J. P. Majoral, J. Chem. Soc. Chem. Commun. 1994, 2161-2162.

[34] M. Badri, A. M. Caminade, J. P. Majoral, A. Gorgues, Phosphorus Sulfur Silicon Relat. Elem. 1991, 56, 123-127.

[35] A. M. Caminade, J. P. Majoral, Chem. Rev. 1994, 94, 1183-1213.

[36] a) E. Buhleier, W. Wehner, F. Voegtle, Synthesis 1978, 155-158; b) D. A. Tomalia, H. Baker, J. Dewald, M. Hall, G. Kallos, S. Martin, J. Roeck, J. Ryder, P. Smith, Polymer J. 1985, 17, 117-132; c) G. R. Newkome, Z. Yao, G. R. Baker, V. K. Gupta, J. Org. Chem. 1985, 50, 2003-2004.

[37] C. Hawker, J. M. J. Frechet, J. Chem. Soc. Chem. Commun. 1990 1010-1013.

[38] See in particular the themed collection in Chem. Soc. Rev. about dendrimers and hyperbranched polymers, 2015 (http://pubs.rsc.org/en/journals/articlecollectionlanding?sercode=cs\&the meid=fda02c85-d70f-40eb-81bd-4b5e4b97869a) accessed 30 August 2018.

[39] a) J. P. Majoral, A. M. Caminade, Chem. Rev. 1999, 99, 845-880; b) J. P. Majoral, A. M. Caminade, V. Maraval, Chem. Commun. 2002, 2929 2942; c) A. M. Caminade, Chem. Soc. Rev. 2016, 45, 5174-5186.

[40] Dendrimers. Towards Catalytic, Material and Biomedical Uses (Eds. A. M. Caminade, C. O. Turrin, R. Laurent, A. Ouali, B. Delavaux-Nicot), John Wiley \& Sons, Chichester (UK), 2011, pp 1-528.

[41] Phosphorous Dendrimers in Biology and Nanomedicine: Syntheses, Characterization, and Properties (Eds. A. M. Caminade, C. O. Turrin, J P. Majoral) Pan Stanford Publishing, Singapore, 2018, pp 1-372.
[42] a) M. L. Lartigue, N. Launay, B. Donnadieu, A. M. Caminade, J. P. Majoral, Bull. Soc. Chim. Fr. 1997, 134, 981-988; M. L. Lartigue, A. M. Caminade, J. P. Majoral, Phosphorus Sulfur Silicon Relat. Elem. 1997, 123, 21-34

[43] N. Launay, A. M. Caminade, R. Lahana, J. P. Majoral, Angew. Chem. 1994, 106, 1682-1684; Angew. Chem.-Int. Edit. Engl. 1994, 33, 1589 1592

[44] N. Launay, A. M. Caminade, J. P. Majoral, J. Am. Chem. Soc. 1995 117, 3282-3283

[45] M. Slany, M. Bardaji, M. J. Casanove, A. M. Caminade, J. P. Majoral, B. Chaudret, J. Am. Chem. Soc. 1995, 117, 9764-9765.

[46] M. L. Lartigue, B. Donnadieu, C. Galliot, A. M. Caminade, J. P. Majoral, J. P. Fayet, Macromolecules 1997, 30, 7335-7337.

[47] N. Launay, A. M. Caminade, J. P. Majoral, J. Organomet. Chem. 1997, 529, 51-58.

[48] a) A.-M. Caminade, A. Ouali, A. Hameau, R. Laurent, C. Rebout, B. Delavaux-Nicot, C.-O. Turrin, K. M. Chane-Ching, J.-P. Majoral, Pure Appl. Chem. 2016, 88, 919-929; b) A.-M. Caminade, A. Hameau, J.-P. Majoral, Dalton Trans. 2016, 45, 1810-1822.

[49] M. Keller, V. Colliere, O. Reiser, A. M. Caminade, J. P. Majoral, A Ouali, Angew. Chem. 2013, 125, 3714-3717; Angew. Chem. Int. Ed. 2013, 52, 3626-3629.

[50] a) D. Riegert, A. Pla-Quintana, S. Fuchs, R. Laurent, C. O. Turrin, C. Duhayon, J. P. Majoral, A. Chaumonnot, A. M. Caminade, Eur. J. Org Chem. 2013, 2013, 5414-5422; b) D. Riegert, L. Bareille, R. Laurent, J. P. Majoral, A. M. Caminade, A. Chaumonnot, Eur. J. Inorg. Chem. 2016, 3103-3110

[51] E. Martinez-Ferrero, G. Franc, S. Mazeres, C. O. Turrin, U. Boissiere, A. M. Caminade, J. P. Majoral, C. Sanchez, Chem.-Eur. J. 2008, 14 7658-7669.

[52] A. Hameau, S. Fuchs, R. Laurent, J. P. Majoral, A. M. Caminade, Beilstein J. Org. Chem. 2011, 7, 1577-1583.

[53] S. Fuchs, A. Pla-Quintana, S. Mazeres, A. M. Caminade, J. P. Majoral, Org. Lett. 2008, 10, 4751-4754

[54] M. Tristany, R. Laurent, H. Dib, L. Gonsalvi, M. Peruzzini, J. P. Majoral, A. M. Caminade, Inorg. Chim. Acta 2014, 409, 121-126

[55] V. Maraval, A. M. Caminade, J. P. Majoral, J. C. Blais, Angew. Chem. 2003, 115, 1866-1870; Angew. Chem. Int. Ed. 2003, 42, 1822-1826.

[56] O. Rolland, L. Griffe, M. Poupot, A. Maraval, A. Ouali, Y. Coppel, J. J. Fournie, G. Bacquet, C. O. Turrin, A. M. Caminade, J. P. Majoral, R Poupot, Chem.-Eur. J. 2008, 14, 4836-4850.

[57] E. R. de Jong, N. Deloch, W. Knoll, C. O. Turrin, J. P. Majoral, A. M Caminade, I. Koper, New J. Chem. 2015, 39, 7194-7205.

[58] T. R. Krishna, M. Parent, M. H. V. Werts, L. Moreaux, S. Gmouh, S. Charpak, A. M. Caminade, J. P. Majoral, M. Blanchard-Desce, Angew. Chem. 2006, 118, 4761-4764; Angew. Chem. Int. Ed. 2006, 45, 4645 4648

[59] a) O. Mongin, C. Rouxel, A. C. Robin, A. Pla-Quintana, T. R. Krishna, G. Recher, F. Tiaho, A. M. Caminade, J. P. Majoral, M. Blanchard-Desce, in Nanobiosystems: Processing, Characterization, and Applications, Vol. 7040 (Eds.: E. M. Heckman, T. B. Singh, J. Yoshida), Spie-Int Soc Optical Engineering, Bellingham, 2008; b) C. Rouxel, M. Charlot, O. Mongin, T. R. Krishna, A. M. Caminade, J. P. Majoral, M. Blanchard Desce, Chem.-Eur. J. 2012, 18, 16450-16462.

[60] a) J. Leclaire, Y. Coppel, A. M. Caminade, J. P. Majoral, J. Am. Chem Soc. 2004, 126, 2304-2305; b) J. Leclaire, R. Dagiral, S. Fery-Forgues, Y. Coppel, B. Donnadieu, A. M. Caminade, J. P. Majoral, J. Am. Chem. Soc. 2005, 127, 15762-15770; c) J. Leclaire, R. Dagiral, A. Pla Quintana, A. M. Caminade, J. P. Majoral, Eur. J. Inorg. Chem. 2007, 2890-2896.

[61] G. Spataro, F. Malecaze, C. O. Turrin, V. Soler, C. Duhayon, P. P Elena, J. P. Majoral, A. M. Caminade, Eur. J. Med. Chem. 2010, 45, 326-334. 
[62] C. O. Turrin, J. Chiffre, D. de Montauzon, J. C. Daran, A. M. Caminade, E. Manoury, G. Balavoine, J. P. Majoral, Macromolecules 2000, 33 7328-7336.

[63] V. R. Maraval, D. Prevote-Pinet, R. Laurent, A. M. Caminade, J. P. Majoral, New J. Chem. 2000, 24, 561-566.

[64] N. G. Garcia-Pena, A. M. Caminade, A. Ouali, R. Redon, C. O. Turrin, RSC Advances 2016, 6, 64557-64567.

[65] L. Brauge, V. Maraval, R. Laurent, A. M. Caminade, J. P. Majoral, Arkivoc 2002, 151-160.

[66] C. Barriere, V. Latour, P. Fau, A. M. Caminade, C. O. Turrin, Tetrahedron Lett. 2012, 53, 1908-1911.

[67] C. O. Turrin, V. Maraval, A. M. Caminade, J. P. Majoral, A. Mehdi, C. Reye, Chem. Mater. 2000, 12, 3848-3856.

[68] V. Maraval, R. Laurent, B. Donnadieu, M. Mauzac, A. M. Caminade, J. P. Majoral, J. Am. Chem. Soc. 2000, 122, 2499-2511.

[69] R. M. Sebastian, L. Griffe, C. O. Turrin, B. Donnadieu, A. M. Caminade, J. P. Majoral, Eur. J. Inorg. Chem. 2004, 2459-2466.

[70] C. O. Turrin, B. Donnadieu, A. M. Caminade, J. P. Majoral, Zeitschrift Fur Anorganische Und Allgemeine Chemie 2005, 631, 2881-2887.

[71] C. Larre, A. M. Caminade, J. P. Majoral, Angew. Chem. 1997, 109 613-617; Angew. Chem.-Int. Edit. Engl. 1997, 36, 596-599.

[72] E. Badetti, G. Franc, J. P. Majoral, A. M. Caminade, R. M. Sebastian, Synthesis-Stuttgart 2011, 1427-1434.

[73] V. Maraval, R. Laurent, B. Donnadieu, A. M. Caminade, J. P. Majoral, Synthesis-Stuttgart 2003, 389-396.

[74] V. Maraval, R. Laurent, S. Merino, A. M. Caminade, J. P. Majoral, Eur. J. Org. Chem. 2000, 3555-3568.

[75] a) C. O. Turrin, J. Chiffre, J. C. Daran, D. de Montauzon, G. Balavoine, E. Manoury, A. M. Caminade, J. P. Majoral, C. R. Chim. 2002, 5, 309318; b) E. R. de Jong, E. Manoury, J. C. Daran, C. O. Turrin, J. Chiffre, A. Sournia-Saquet, W. Knoll, J. P. Majoral, A. M. Caminade, J Organomet. Chem. 2012, 718, 22-30.

[76] a) C. O. Turrin, J. Chiffre, D. de Montauzon, G. Balavoine, E. Manoury, A. M. Caminade, J. P. Majoral, Organometallics 2002, 21, 1891-1897; b) C. O. Turrin, J. Chiffre, J. C. Daran, D. de Montauzon, A. M. Caminade, E. Manoury, G. Balavoine, J. P. Majoral, Tetrahedron 2001, 57, 2521-2536

[77] G. Magro, P. Marchand, R. M. Sebastian, C. Guyard-Duhayon, A. M. Caminade, J. P. Majoral, Eur. J. Org. Chem. 2005, 1340-1347.

[78] A. M. Caminade, S. Fruchon, C. O. Turrin, M. Poupot, A. Ouali, A Maraval, M. Garzoni, M. Maly, V. Furer, V. Kovalenko, J. P. Majoral, G. M. Pavan, R. Poupot, Nature Communications 2015, 6, 7722

[79] a) R. M. Sebastian, J. C. Blais, A. M. Caminade, J. P. Majoral, Chem. Eur. J. 2002, 8, 2172-2183; b) R. Deloncle, A. M. Caminade, Journal of Photochemistry and Photobiology C-Photochemistry Reviews 2010, 11 25-45.

[80] O. Mongin, C. Rouxel, J. M. Vabre, Y. Mir, A. Pla-Quintana, Y. Q. Wei, A. M. Caminade, J. P. Majoral, M. Blanchard-Desce, in Nanobiosystems: Processing, Characterization, and Applications li, Vol. 7403 (Eds.: N. Kobayashi, F. Ouchen, I. Rau), Spie-Int Soc Optical Engineering, Bellingham, 2009.

[81] S. Mignani, N. El Brahmi, L. Eloy, J. Poupon, V. Nicolas, A. Steinmetz, S. El Kazzouli, M. M. Bousmina, M. Blanchard-Desce, A. M. Caminade, J. P. Majoral, T. Cresteil, Eur. J. Med. Chem. 2017, 132, 142-156.

[82] P. Servin, C. Rebout, R. Laurent, M. Peruzzini, A. M. Caminade, J. P. Majoral, Tetrahedron Lett. 2007, 48, 579-583.

[83] H. Dib, C. Rebout, R. Laurent, S. Mallet-Ladeira, A. Sournia-Saquet, M. B. Sarosi, E. Hey-Hawkins, J.-P. Majoral, B. Delavaux-Nicot, A.-M Caminade, Chem.-Eur. J. 2016, 22, 10736-10742.

[84] C. Larre, B. Donnadieu, A. M. Caminade, J. P. Majoral, Chem.-Eur. J. 1998, 4, 2031-2036.

[85] a) C. Larre, B. Donnadieu, A. M. Caminade, J. P. Majoral, J. Am. Chem Soc. 1998, 120, 4029-4030; b) C. Larre, D. Bressolles, C. Turrin, B. Donnadieu, A. M. Caminade, J. P. Majoral, J. Am. Chem. Soc. 1998 $120,13070-13082$
[86] C. Larre, B. Donnadieu, A. M. Caminade, J. P. Majoral, Eur. J. Inorg. Chem. 1999, 601-611.

[87] a) A. M. Caminade, R. Laurent, J. P. Majoral, Adv. Drug Delivery Rev. 2005, 57, 2130-2146; b) A. M. Caminade, R. Laurent, C. O. Turrin, C Rebout, B. Delavaux-Nicot, A. Ouali, M. Zablocka, J. P. Majoral, C. R Chim. 2010, 13, 1006-1027.

[88] L. Brauge, A. M. Caminade, J. P. Majoral, S. Slomkowski, M. Wolszczak, Macromolecules 2001, 34, 5599-5606.

[89] V. Cadierno, A. Igau, B. Donnadieu, A. M. Caminade, J. P. Majoral, Organometallics 1999, 18, 1580-1582.

[90] C. Galliot, C. Larre, A. M. Caminade, J. P. Majoral, Science 1997, 277 , 1981-1984.

[91] J. P. Majoral, C. Larre, R. Laurent, A. M. Caminade, Coord. Chem. Rev. 1999, 192, 3-18.

[92] A.-M. Caminade, J.-P. Majoral, J. Nanoparticle Research 2018, 20, 74.

[93] a) V. Maraval, A. Maraval, G. Spataro, A. M. Caminade, J. P. Majoral, D. H. Kim, W. Knoll, New J. Chem. 2006, 30, 1731-1736; b) A. M. Caminade, R. Laurent, B. Delavaux-Nicot, J. P. Majoral, New J. Chem. 2012, 36, 217-226; c) S. Gottis, L. I. Rodriguez, R. Laurent, I. Angurell, M. Seco, O. Rossell, J. P. Majoral, A. M. Caminade, Tetrahedron Lett. 2013, 54, 6864-6867; d) O. J. Lee, V. Maraval, A. M. Caminade, K. Chung, K. H. A. Lau, K. Shin, J. P. Majoral, W. Knoll, D. H. Kim, Macromol. Res. 2016, 24, 851-855.

[94] C. Galliot, D. Prevote, A. M. Caminade, J. P. Majoral, J. Am. Chem. Soc. 1995, 117, 5470-5476.

[95] R. M. Sebastian, G. Magro, A. M. Caminade, J. P. Majoral, Tetrahedron 2000, 56, 6269-6277.

[96] a) R. Sharma, N. Kottari, Y. M. Chabre, L. Abbassi, T. C. Shiao, R. Roy, Chem. Commun. 2014, 50, 13300-13303; b) R. S. Bagul, M. M. Hosseini, T. C. Shiao, R. Roy, Can. J. Chem. 2017, 95, 975-983.

[97] N. Katir, N. El Brahmi, A. El Kadib, S. Mignani, A. M. Caminade, M. Bousmina, J. P. Majoral, Chem.-Eur. J. 2015, 21, 6400-6408.

[98] a) L. Brauge, G. Magro, A. M. Caminade, J. P. Majoral, J. Am. Chem. Soc. 2001, 123, 6698-6699; b) L. Brauge, G. Magro, A. M. Caminade, J. P. Majoral, J. Am. Chem. Soc. 2001, 123, 8446-8446; c) V. Maraval, J. Pyzowski, A. M. Caminade, J. P. Majoral, J. Org. Chem. 2003, 68, 6043-6046.

[99] a) K. Ciepluch, N. Katir, A. El Kadib, A. Felczak, K. Zawadzka, M. Weber, B. Klajnert, K. Lisowska, A. M. Caminade, M. Bousmina, M Bryszewska, J. P. Majoral, Mol. Pharm. 2012, 9, 448-457; b) N. Katir, J. P. Majoral, A. El Kadib, A. M. Caminade, M. Bousmina, Eur. J. Org Chem. 2012, 269-273

[100] S. Moreno, A. Szwed, N. El Brahmi, K. Milowska, J. Kurowska, E. Fuentes-Paniagua, E. Pedziwiatr-Werbicka, T. Gabryelak, N. Katir, F. J de la Mata, M. A. Munoz-Fernandez, R. Gomez-Ramirez, A. M. Caminade, J. P. Majoral, M. Bryszewska, RSC Advances 2015, 5, 25942-25958.

[101] a) C. Marmillon, F. Gauffre, T. Gulik-Krzywicki, C. Loup, A. M. Caminade, J. P. Majoral, J. P. Vors, E. Rump, Angew. Chem. 2001 113, 2696-2699; Angew. Chem. Int. Ed. 2001, 40, 2626-2629; b) A. E Ghzaoui, F. Gauffre, A. M. Caminade, J. P. Majoral, H. Lannibois Drean, Langmuir 2004, 20, 9348-9353; c) C. Larpent, C. Genies, A. P D. Delgado, A. M. Caminade, J. P. Majoral, J. F. Sassi, F. Leising Chem. Commun. 2004, 1816-1817.

[102] a) G. Schmid, W. Meyer-Zaika, R. Pugin, T. Sawitowski, J. P. Majoral A. M. Caminade, C. O. Turrin, Chem.-Eur. J. 2000, 6, 1693-1697; b) G. Schmid, E. Emmrich, J. P. Majoral, A. M. Caminade, Small 2005, 1, 73 75 .

[103] a) E. Badetti, V. Lloveras, K. Wurst, R. M. Sebastian, A. M. Caminade, J. P. Majoral, J. Veciana, J. Vidal-Gancedo, Org. Lett. 2013, 15, 3490 3493; b) E. Badetti, V. Lloveras, J. L. Munoz-Gomez, R. M. Sebastian, A. M. Caminade, J. P. Majoral, J. Veciana, J. Vidal-Gancedo Macromolecules 2014, 47, 7717-7724.

[104] R. Goller, J. P. Vors, A. M. Caminade, J. P. Majoral, Tetrahedron Lett. 2001, 42, 3587-3590. 
[105] A. Kanibolotsky, S. Roquet, M. Cariou, P. Leriche, C. O. Turrin, R. de Bettignies, A. M. Caminade, J. P. Majoral, V. Khodorkovsky, A Gorgues, Org. Lett. 2004, 6, 2109-2112.

[106] P. Servin, R. Laurent, L. Gonsalvi, M. Tristany, M. Peruzzini, J. P. Majoral, A. M. Caminade, Dalton Trans. 2009, 4432-4434.

[107] C. A. Hincapie, R. M. Sebastian, J. Barbera, J. L. Serrano, T. Sierra, J. P. Majoral, A. M. Caminade, Chem.-Eur. J. 2014, 20, 17047-17058.

[108] L. Garcia, A. Roglans, R. Laurent, J. P. Majoral, A. Pla-Quintana, A. M. Caminade, Chem. Commun. 2012, 48, 9248-9250.

[109] D. Prevote, A. M. Caminade, J. P. Majoral, J. Org. Chem. 1997, 62, 4834-4841.

[110] a) L. Griffe, M. Poupot, P. Marchand, A. Maraval, C. O. Turrin, O. Rolland, P. Metivier, G. Bacquet, J. J. Fournie, A. M. Caminade, R Poupot, J. P. Majoral, Angew. Chem. 2007, 119, 2575-2578; Angew. Chem. Int. Ed. 2007, 46, 2523-2526; b) P. Marchand, L. Griffe, M. Poupot, C. O. Turrin, G. Bacquet, J. J. Fournie, J. P. Majoral, R. Poupot, A. M. Caminade, Bioorg. Med. Chem. Lett. 2009, 19, 3963-3966.

[111] a) M. L. Lartigue, M. Slany, A. M. Caminade, J. P. Majoral, Chem.-Eur. J. 1996, 2, 1417-1426; b) N. Launay, M. Slany, A. M. Caminade, J. P. Majoral, J. Org. Chem. 1996, 61, 3799-3805.

[112] D. Prevote, S. LeRoyGourvennec, A. M. Caminade, S. Masson, J. P. Majoral, Synthesis-Stuttgart 1997, 1199-1207.

[113] a) R. M. Sebastian, A. M. Caminade, J. P. Majoral, E. Levillain, L. Huchet, J. Roncali, Chem. Commun. 2000, 507-508; b) F. Le Derf, E. Levillain, G. Trippe, A. Gorgues, M. Salle, R. M. Sebastian, A. M. Caminade, J. P. Majoral, Angew. Chem. 2001, 113, 230-233; Angew. Chem. Int. Ed. 2001, 40, 224-227.

[114] G. Soler-Illia, L. Rozes, M. K. Boggiano, C. Sanchez, C. O. Turrin, A. M. Caminade, J. P. Majoral, Angew. Chem. 2000, 112, 4419-4424; Angew. Chem. Int. Ed. 2000, 39, 4250-4254.

[115] a) M. Blanzat, C. O. Turrin, E. Perez, I. Rico-Lattes, A. M. Caminade, J. P. Majoral, Chem. Commun. 2002, 1864-1865; b) M. Blanzat, C. O. Turrin, A. M. Aubertin, C. Couturier-Vidal, A. M. Caminade, J. P. Majoral, I. Rico-Lattes, A. Lattes, ChemBioChem 2005, 6, 2207-2213.

[116] L. Routaboul, S. Vincendeau, C. O. Turrin, A. M. Caminade, J. P. Majoral, J. C. Daran, E. Manoury, J. Organomet. Chem. 2007, 692, 1064-1073.

[117] a) P. Neumann, H. Dib, A. M. Caminade, E. Hey-Hawkins, Angew. Chem. 2015, 127, 316-319; Angew. Chem. Int. Ed. 2015, 54, 311-314 b) P. Neumann, H. Dib, A. Sournia-Saquet, T. Grell, M. Handke, A. M. Caminade, E. Hey-Hawkins, Chem.-Eur. J. 2015, 21, 6590-6604.

[118] M. Poupot, L. Griffe, P. Marchand, A. Maraval, O. Rolland, L. Martinet, F. E. L'Faqihi-Olive, C. O. Turrin, A. M. Caminade, J. J. Fournie, J. P. Majoral, R. Poupot, FASEB J. 2006, 20, 2339-2351.

[119] a) A. Perez-Anes, G. Spataro, Y. Coppel, C. Moog, M. Blanzat, C. O. Turrin, A. M. Caminade, I. Rico-Lattes, J. P. Majoral, Org. Biomol. Chem. 2009, 7, 3491-3498; b) A. Perez-Anes, C. Stefaniu, C. Moog, J. P. Majoral, M. Blanzat, C. O. Turrin, A. M. Caminade, I. Rico-Lattes, Bioorg. Med. Chem. 2010, 18, 242-248.

[120] O. Rolland, C. O. Turrin, G. Bacquet, R. Poupot, M. Poupot, A. M. Caminade, J. P. Majoral, Tetrahedron Lett. 2009, 50, 2078-2082.

[121] E. Blattes, A. Vercellone, H. Eutamene, C. O. Turrin, V. Theodorou, J. P. Majoral, A. M. Caminade, J. Prandi, J. Nigou, G. Puzo, Proc. Natl. Acad. Sci. U. S. A. 2013, 110, 8795-8800.

[122] a) N. El Brahmi, S. M. Mignani, J. Caron, S. El Kazzouli, M. M. Bousmina, A. M. Caminade, T. Cresteil, J. P. Majoral, Nanoscale 2015 7, 3915-3922; b) S. Mignani, N. El Brahmi, S. El Kazzouli, L. Eloy, D. Courilleau, J. Caron, M. M. Bousmina, A. M. Caminade, T. Cresteil, J. P. Majoral, Eur. J. Med. Chem. 2016, 122, 656-673.

[123] a) I. Angurell, C. O. Turrin, R. Laurent, V. Maraval, P. Servin, O. Rossell, M. Seco, A. M. Caminade, J. P. Majoral, J. Organomet. Chem 2007, 692, 1928-1939; b) P. Servin, R. Laurent, A. Romerosa, M. Peruzzini, J. P. Majoral, A. M. Caminade, Organometallics 2008, 27, 2066-2073.
[124] M. Keller, A. Hameau, G. Spataro, S. Ladeira, A. M. Caminade, J. P. Majoral, A. Ouali, Green Chem. 2012, 14, 2807-2815.

[125] G. Franc, S. Mazeres, C. O. Turrin, L. Vendier, C. Duhayon, A. M. Caminade, J. P. Majoral, J. Org. Chem. 2007, 72, 8707-8715.

[126] Y. Q. Wei, R. Laurent, J. P. Majoral, A. M. Caminade, Arkivoc 2010 318-327.

[127] A. Balueva, S. Merino, A. M. Caminade, J. P. Majoral, J. Organomet. Chem. 2002, 643, 112-124

[128] M. Koprowski, R. M. Sebastian, V. Maraval, M. Zablocka, V. Cadierno, B. Donnadieu, A. Igau, A. M. Caminade, J. P. Majoral, Organometallics 2002, 21, 4680-4687.

[129] a) M. Keller, M. lanchuk, S. Ladeira, M. Taillefer, A. M. Caminade, J. P. Majoral, A. Ouali, Eur. J. Org. Chem. 2012, 1056-1062; C. Rouxel, O Mongin, A. Hameau, A. Ouali, M. Blanchard-Desce, J. P. Majoral, A. M. Caminade, Can. J. Chem. 2017, 95, 948-953.

[130] A. Ouali, R. Laurent, A. M. Caminade, J. P. Majoral, M. Taillefer, J. Am. Chem. Soc. 2006, 128, 15990-15991.

[131] A. Perrier, M. Keller, A. M. Caminade, J. P. Majoral, A. Ouali, Green Chem. 2013, 15, 2075-2080.

[132] A. Gissibl, C. Padie, M. Hager, F. Jaroschik, R. Rasappan, E. CuevasYanez, C. O. Turrin, A. M. Caminade, J. P. Majoral, O. Reiser, Org. Lett. 2007, 9, 2895-2898.

[133] M. Keller, A. Perrier, R. Linhardt, L. Travers, S. Wittmann, A. M. Caminade, J. P. Majoral, O. Reiser, A. Ouali, Adv. Synth. Catal. 2013 355, 1748-1754

[134] J. Rull, M. Casals, R. M. Sebastian, A. Vallribera, J. P. Majoral, A. M Caminade, Chemcatchem 2015, 7, 2698-2704.

[135] M. A. Lacour, M. Zablocka, A. M. Caminade, M. Taillefer, J. P. Majoral, Tetrahedron Lett. 2009, 50, 4870-4873.

[136] V. Darcos, A. Dureault, D. Taton, Y. Gnanou, P. Marchand, A. M. Caminade, J. P. Majoral, M. Destarac, F. Leising, Chem. Commun. 2004, 2110-2111.

[137] P. Marchand, L. Griffe, A. M. Caminade, J. P. Majoral, M. Destarac, F Leising, Org. Lett. 2004, 6, 1309-1312.

[138] N. El Brahmi, S. El Kazzouli, S. Mignani, R. Laurent, S. Ladeira, A. M. Caminade, M. Bousmina, J. P. Majoral, Tetrahedron 2017, 73, 1331 1341.

[139] a) C. O. Turrin, V. Maraval, J. Leclaire, E. Dantras, C. Lacabanne, A. M. Caminade, J. P. Majoral, Tetrahedron 2003, 59, 3965-3973; b) A. M Caminade, C. O. Turrin, P. Sutra, J. P. Majoral, Curr. Opin. Colloid Interface Sci. 2003, 8, 282-295.

[140] F. Terenziani, V. Parthasarathy, A. Pla-Quintana, T. Maishal, A. M. Caminade, J. P. Majoral, M. Blanchard-Desce, Angew. Chem. 2009, 121, 8847-8850; Angew. Chem. Int. Ed. 2009, 48, 8691-8694.

[141] a) O. Mongin, T. R. Krishna, M. H. V. Werts, A. M. Caminade, J. P. Majoral, M. Blanchard-Desce, Chem.Commun. 2006, 915-917; b) O Mongin, A. Pla-Quintana, F. Terenziani, D. Drouin, C. Le Droumaguet, A. M. Caminade, J. P. Majoral, M. Blanchard-Desce, New J. Chem. 2007, 31, 1354-1367.

[142] E. Cavero, M. Zablocka, A. M. Caminade, J. P. Majoral, Eur. J. Org Chem. 2010, 2759-2767.

[143] C. Hadad, J. P. Majoral, J. Muzart, A. M. Caminade, S. Bouquillon, Tetrahedron Lett. 2009, 50, 1902-1905.

[144] G. Franc, C. O. Turrin, E. Cavero, J. P. Costes, C. Duhayon, A. M. Caminade, J. P. Majoral, Eur. J. Org. Chem. 2009, 4290-4299.

[145] C. Loup, M. A. Zanta, A. M. Caminade, J. P. Majoral, B. Meunier Chem.-Eur. J. 1999, 5, 3644-3650.

[146] C. Padie, M. Maszewska, K. Majchrzak, B. Nawrot, A. M. Caminade, J. P. Majoral, New J. Chem. 2009, 33, 318-326.

[147] M. Slany, A. M. Caminade, J. P. Majoral, Tetrahedron Lett. 1996, 37 , 9053-9056.

[148] A. M. Caminade, J. P. Majoral, New J. Chem. 2013, 37, 3358-3373.

[149] D. Prevote, B. Donnadieu, M. Moreno-Manas, A. M. Caminade, J. P. Majoral, Eur. J. Org. Chem. 1999, 1701-1708. 
[150] G. Franc, E. Badetti, V. Colliere, J. P. Majoral, R. M. Sebastian, A. M. Caminade, Nanoscale 2009, 1, 233-237.

[151] M. Severac, J. Leclaire, P. Sutra, A. M. Caminade, J. P. Majoral, Tetrahedron Lett. 2004, 45, 3019-3022.

[152] a) A. M. Caminade, P. Servin, R. Laurent, J. P. Majoral, Chem. Soc. Rev. 2008, 37, 56-67.; b) A. M. Caminade, A. Ouali, R. Laurent, C. O Turrin, J. P. Majoral, Coord. Chem. Rev. 2016, 308, 478-497.

[153] W. Knoll, A. M. Caminade, K. Char, H. Duran, C. L. Feng, A. Gitsas, D. H. Kim, A. Lau, T. D. Lazzara, J. P. Majoral, M. Steinhart, B. Yameen, X. H. Zhong, Small 2011, 7, 1384-1391.

[154] A. M. Caminade, A. Hameau, J. P. Majoral, Chem.-Eur. J. 2009, 15, 9270-9285.

[155] a) O. Rolland, C. O. Turrin, A. M. Caminade, J. P. Majoral, New J. Chem. 2009, 33, 1809-1824; b) A. M. Caminade, C. O. Turrin, J. P. Majoral, New J. Chem. 2010, 34, 1512-1524; c) A. M. Caminade, C. O Turrin, J. Materials Chemistry B 2014, 2, 4055-4066; d) A.-M. Caminade, Chem. Commun. 2017, 53, 9830-9838.

[156] a) M. Bardaji, A. M. Caminade, J. P. Majoral, B. Chaudret, Organometallics 1997, 16, 3489-3497; b) M. Slany, M. Bardaji, A. M. Caminade, B. Chaudret, J. P. Majoral, Inorg. Chem. 1997, 36, 1939 1945; c) A. M. Caminade, R. Laurent, B. Chaudret, J. P. Majoral, Coord Chem. Rev. 1998, 178, 793-821; d) V. Maraval, R. Laurent, A. M. Caminade, J. P. Majoral, Organometallics 2000, 19, 4025-4029; e) R. Laurent, A. M. Caminade, J. P. Majoral, Tetrahedron Lett. 2005, 46, 6503-6506; f) M. Zablocka, A. Hameau, A. M. Caminade, J. P. Majoral Adv. Synth. Catal. 2010, 352, 2341-2358; g) P. Servin, R. Laurent, H. Dib, L. Gonsalvi, M. Peruzzini, J. P. Majoral, A. M. Caminade, Tetrahedron Lett. 2012, 53, 3876-3879; h) P. Servin, R. Laurent, M. Tristany, A. Romerosa, M. Peruzzini, F. Garcia-Maroto, J.-P. Majoral A.-M. Caminade, Inorg. Chim. Acta 2018, 470, 106-112.

[157] A. M. Caminade, A. Ouali, R. Laurent, C. O. Turrin, J. P. Majoral, Chem. Soc. Rev. 2015, 44, 3890-3899.

[158] A. Perrier, M. Keller, A. M. Caminade, J. P. Majoral, A. Ouali, Green Chem. 2013, 15, 2075-2080.

[159] A. M. Allgeier, C. A. Mirkin, Angew. Chem. 1998, 110, 936-952; Angew. Chem. Int. Ed. 1998, 37, 894-908.

[160] A. M. Caminade, V. Maraval, R. Laurent, J. P. Majoral, Curr. Org Chem. 2002, 6, 739-774.

[161] A. M. Caminade, A. Ouali, M. Keller, J. P. Majoral, Chem. Soc. Rev. 2012, 41, 4113-4125.

[162] J. Rull, J. J. Jara, R. M. Sebastian, A. Vallribera, C. Najera, J. P. Majoral, A. M. Caminade, Chemcatchem 2016, 8, 2049-2056.

[163] A. M. Caminade, J. P. Majoral, Acc. Chem. Res. 2004, 37, 341-348.

[164] P. Reinert, J. Y. Chane-Ching, L. Bull, R. Dagiral, P. Batail, R. Laurent, A. M. Caminade, J. P. Majoral, New J. Chem. 2007, 31, 1259-1263.

[165] Y. Brahmi, N. Katir, A. Hameau, A. Essoumhi, E. Essassi, A. M. Caminade, M. Bousmina, J. P. Majoral, A. El Kadib, Chem. Commun. 2011, 47, 8626-8628.

[166] Y. Brahmi, N. Katir, M. lanchuk, V. Colliere, E. Essassi, A. Ouali, A. M. Caminade, M. Bousmina, J. P. Majoral, A. El Kadib, Nanoscale 2013, 5 2850-2856.

[167] A. Beraa, M. Hajjaji, R. Laurent, B. Delavaux-Nicot, A. M. Caminade, Desalin. Water Treat. 2016, 57, 14290-14303.

[168] A. Beraa, M. Hajjaji, R. Laurent, A. M. Caminade, Appl. Clay Sci. 2017, 136, 142-151.

[169] J. P. Majoral, M. Zablocka, A.-M. Caminade, P. Balczewski, X. Shi, S. Mignani, Coord. Chem. Rev. 2018, 358, 80-91.

[170] E. Badetti, A. M. Caminade, J. P. Majoral, M. Moreno-Manas, R. M. Sebastian, Langmuir 2008, 24, 2090-2101.

[171] E. Badetti, G. Franc, J. P. Majoral, A. M. Caminade, R. M. Sebastian, M. Moreno-Manas, Eur. J. Org. Chem. 2011, 1256-1265.

[172] G. Franc, E. Badetti, C. Duhayon, Y. Coppel, C. O. Turrin, J. P. Majoral, R. M. Sebastian, A. M. Caminade, New J. Chem. 2010, 34, 547-555.

[173] A. Hameau, V. Colliere, J. Grimoud, P. Fau, C. Roques, A. M. Caminade, C. O. Turrin, RSC Advances 2013, 3, 19015-19026.
[174] E. Folgado, M. Guerre, C. Bijani, V. Ladmiral, A. M. Caminade, B. Ameduri, A. Ouali, Polymer Chemistry 2016, 7, 5625-5629.

[175] N. Katir, N. El Brahmi, N. Marcotte, J. P. Majoral, M. Bousmina, A. E Kadib, Macromolecules 2016, 49, 5796-5805

[176] A. M. Caminade, J. P. Majoral, Chem. Soc. Rev. 2010, 39, 2034-2047.

[177] D. H. Kim, P. Karan, P. Goring, J. Leclaire, A. M. Caminade, J. P. Majoral, U. Gosele, M. Steinhart, W. Knoll, Small 2005, 1, 99-102.

[178] a) C. L. Feng, X. H. Zhong, M. Steinhart, A. M. Caminade, J. P. Majoral, W. Knoll, Adv. Mater. 2007, 19, 1933-1936; b) C. L. Feng, X. H. Zhong M. Steinhart, A. M. Caminade, J. P. Majoral, W. Knoll, Small 2008, 4 566-571.

[179] T. D. Lazzara, K. H. A. Lau, A. I. Abou-Kandil, A. M. Caminade, J. P. Majoral, W. Knoll, ACS Nano 2010, 4, 3909-3920.

[180] F. Yu, S. Ahl, A. M. Caminade, J. P. Majoral, W. Knoll, J. Erlebacher, Anal. Chem. 2006, 78, 7346-7350.

[181] B. S. Kim, O. V. Lebedeva, D. H. Kim, A. M. Caminade, J. P. Majoral, W. Knoll, O. I. Vinogradova, Langmuir 2005, 21, 7200-7206.

[182] B. S. Kim, O. V. Lebedeva, M. K. Park, W. Knoll, A. M. Caminade, J. P. Majoral, O. I. Vinogradova, Polymer 2010, 51, 4525-4529.

[183] ${ }^{1}$ a) C. L. Feng, A. M. Caminade, J. P. Majoral, J. J. Gu, S. M. Zhu, H. L. Su, X. B. Hu, D. Zhang, Analyst 2010, 135, 2939-2944; b) C. L. Feng, A. M. Caminade, J. P. Majoral, D. Zhang, J. Mater. Chem. 2010, 20, 14381441

[184] B. S. Kim, O. V. Lebedeva, K. Koynov, H. F. Gong, A. M. Caminade, J. P. Majoral, O. I. Vinogradova, Macromolecules 2006, 39, 5479-5483.

[185] A. M. Caminade, C. Padie, R. Laurent, A. Maraval, J. P. Majoral, Sensors 2006, 6, 901-914

[186] A. V. Gerasimov, M. A. Ziganshin, A. E. Vandyukov, V. I. Kovalenko, V V. Gorbatchuk, A. M. Caminade, J. P. Majoral, J. Colloid Interface Sci. 2011, 360, 204-210.

[187] W. B. Zhao, J. Park, A. M. Caminade, S. J. Jeong, Y. H. Jang, S. O Kim, J. P. Majoral, J. Cho, D. H. Kim, J. Mater. Chem. 2009, 19, 2006 2012.

[188] A. Narayanan, O. Varnavski, O. Mongin, J. P. Majoral, M. BlanchardDesce, T. Goodson, Nanotechnology 2008, 19, 115502.

[189] a) B. Miksa, S. Slomkowski, M. M. Chehimi, M. Delamar, J. P. Majoral, A. M. Caminade, Colloid Polym. Sci. 1999, 277, 58-65; b) S. Slomkowski, B. Miksa, M. M. Chehimi, M. Delamar, E. Cabet-Deliry, J. P. Majoral, A. M. Caminade, React. Funct. Polym. 1999, 41, 45-57.

[190] V. Le Berre, E. Trevisiol, A. Dagkessamanskaia, S. Sokol, A. M. Caminade, J. P. Majoral, B. Meunier, J. Francois, Nucleic Acids Res. 2003, 31, 8, e88.

[191] E. Trevisiol, V. Le Berre-Anton, J. Leclaire, G. Pratviel, A. M. Caminade, J. P. Majoral, J. M. Francois, B. Meunier, New J. Chem. 2003, 27 1713-1719.

[192] L. Nicu, M. Guirardel, F. Chambosse, P. Rougerie, S. Hinh, E. Trevisiol J. M. Francois, J. P. Majoral, A. M. Caminade, E. Cattan, C. Bergaud Sens. Actuator B-Chem. 2005, 110, 125-136.

[193] B. Chaize, M. Nguyen, T. Ruysschaert, V. le Berre, E. Trevisiol, A. M. Caminade, J. P. Majoral, G. Pratviel, B. Meunier, M. Winterhalter, D. Fournier, Bioconjugate Chem. 2006, 17, 245-247.

[194] E. Jauvert, E. Dague, M. Severac, L. Ressier, A. M. Caminade, J. P. Majoral, E. Trevisiol, Sens. Actuator B-Chem. 2012, 168, 436-441.

[195] J. P. Majoral, J. M. François, R. Fabre, A. Senescau, A. M. Caminade, Science China Mater. 2018, in press.

[196] A. M. Caminade, C. O. Turrin, J. P. Majoral, Chem.-Eur. J. 2008, 14 7422-7432.

[197] Y. M. Yu, C. L. Feng, A. M. Caminade, J. P. Majoral, W. Knoll Langmuir 2009, 25, 13680-13684.

[198] C. L. Feng, M. Z. Yin, D. Zhang, S. M. Zhu, A. M. Caminade, J. P. Majoral, K. Mullen, Macromol. Rapid Commun. 2011, 32, 679-683.

[199] M. J. Archer, B. C. Lin, Z. Wang, D. A. Stenger, Anal. Biochem. 2006, 355, 285-297.

[200] M. J. Archer, D. A. Stenger, B. C. Lin, Open Anal. Chem. J. 2008, 2 , 47-54. 
[201] M. J. Archer, N. Long, B. C. Lin, BMC Research Notes 2010, 3, 109. [202] M. J. Archer, B. C. Lin, J. Biomed. Biotechnol. 2011, ID 910369

[203] J. L. Hernandez-Lopez, H. L. Khor, A. M. Caminade, J. P. Majoral, S. Mittler, W. Knoll, D. H. Kim, Thin Solid Films 2008, 516, 1256-1264.

[204] L. Brauge, G. Veriot, G. Franc, R. Deloncle, A. M. Caminade, J. P. Majoral, Tetrahedron 2006, 62, 11891-11899.

[205] M. Maszewska, J. Leclaire, M. Cieslak, B. Nawrot, A. Okruszek, A. M. Caminade, J. P. Majoral, Oligonucleotides 2003, 13, 193-205.

[206] J. Kazmierczak-Baranska, A. Pietkiewicz, M. Janicka, Y. Q. Wei, C. O. Turrin, J. P. Majoral, B. Nawrot, A. M. Caminade, Nucleosides Nucleotides \& Nucleic Acids 2010, 29, 155-167.

[207] F. lelasi, J. Ledall, A. P. Anes, S. Fruchon, A. M. Caminade, R. Poupot, C. O. Turrin, M. Blanzat, Phys. Chem. Chem. Phys. 2016, 18, 21871 21880.

[208] A. M. Caminade, C. O. Turrin, R. Laurent, C. Rebout, J. P. Majoral, Polym. Int. 2006, 55, 1155-1160.

[209] A. M. Caminade, J. P. Majoral, Prog. Polym. Sci. 2005, 30, 491-505.

[210] A. Shakhbazau, C. Mohanty, D. Shcharbin, M. Bryszewska, A. M. Caminade, J. P. Majoral, J. Alant, R. Midha, J. Controlled Release 2013 172, 841-851.

[211] M. Dabrzalska, A. Janaszewska, M. Zablocka, S. Mignani, J. P. Majoral, B. Klajnert-Maculewicz, Mol. Pharm. 2017, 14, 1821-1830.

[212] M. Dabrzalska, A. Janaszewska, M. Zablocka, S. Mignani, J. P. Majoral, B. Klajnert-Maculewicz, Molecules (Basel, Switzerland) 2017, 22, 345.

[213] M. A. Deriu, N. Tsapis, M. Noiray, G. Grasso, N. El Brahmi, S. Mignani, J. P. Majoral, E. Fattal, A. Danani, Nanoscale 2018, 10, 10952-10962.

[214] A. Bohr, N. Tsapis, I. Andreana, A. Chamarat, C. Foged, C. Delomenie, M. Noiray, N. El Brahmi, J.-P. Majoral, S. Mignani, E. Fattal, Biomacromolecules 2017, 18, 2379-2388.

[215] J. Solassol, C. Crozet, V. Perrier, J. Leclaire, F. Beranger, A. M. Caminade, B. Meunier, D. Dormont, J. P. Majoral, S. Lehmann, J. Gen Virol. 2004, 85, 1791-1799.

[216] B. Klajnert, M. Cortijo-Arellano, J. Cladera, J. P. Majoral, A. M. Caminade, M. Bryszewska, Biochem. Biophys. Res. Commun. 2007 364, 20-25.

[217] a) B. Klajnert, M. Cangiotti, S. Calici, J. P. Majoral, A. M. Caminade, J. Cladera, M. Bryszewska, M. F. Ottaviani, Macromol. Biosci. 2007, 7, 1065-1074; b) M. F. Ottaviani, R. Mazzeo, M. Cangiotti, L. Fiorani, J. P. Majoral, A. M. Caminade, E. Pedziwiatr, M. Bryszewska, B. Klajnert, Biomacromolecules 2010, 11, 3014-3021; c) T. Wasiak, M. lonov, K Nieznanski, H. Nieznanska, O. Klementieva, M. Granell, J. Cladera, J. P. Majoral, A. M. Caminade, B. Klajnert, Mol. Pharm. 2012, 9, 458-469 d) T. Wasiak, M. Marcinkowska, I. Pieszynski, M. Zablocka, A. M. Caminade, J. P. Majoral, B. Klajnert-Maculewicz, New J. Chem. 2015, 39, 4852-4859.

[218] B. Klajnert, M. Cangiotti, S. Calici, M. Ionov, J. P. Majoral, A. M. Caminade, J. Cladera, M. Bryszewska, M. F. Ottaviani, New J. Chem. 2009, 33, 1087-1093.
[219] J. Lazniewska, A. Janaszewska, K. Milowska, A. M. Caminade, S Mignani, N. Katir, A. El Kadib, M. Bryszewska, J. P. Majoral, T. Gabryelak, B. Klajnert-Maculewicz, Molecules 2013, 18, 12222-12240.

[220] K. Ciepluch, M. Weber, N. Katir, A. M. Caminade, A. El Kadib, B. Klajnert, J. P. Majoral, M. Bryszewska, Int. J. Biol. Macromol. 2013, 54, 119-124.

[221] K. Milowska, A. Szwed, M. Zablocka, A. M. Caminade, J. P. Majoral, S. Mignani, T. Gabryelak, M. Bryszewska, Int. J. Pharm. 2014, 474, 42-49.

[222] I. Posadas, L. Romero-Castillo, N. El Brahmi, D. Manzanares, S Mignani, J. P. Majoral, V. Cena, Proc. Natl. Acad. Sci. U. S. A. 2017 114, E7660-E7669.

[223] N. El Brahmi, S. El Kazzouli, S. M. Mignani, E. Essassi, G. Aubert, R Laurent, A. M. Caminade, M. M. Bousmina, T. Cresteil, J. P. Majoral Mol. Pharm. 2013, 10, 1459-1464.

[224] M. F. Ottaviani, N. El Brahmi, M. Cangiotti, C. Coppola, F. Buccella, T. Cresteil, S. Mignani, A. M. Caminade, J. P. Costes, J. P. Majoral, RSC Advances 2014, 4, 36573-36583.

[225] S. M. Mignani, N. El Brahmi, S. El Kazzouli, R. Laurent, S. Ladeira, A. M. Caminade, E. Pedziwiatr-Werbicka, E. M. Szewczyk, M. Bryszewska, M. M. Bousmina, T. Cresteil, J.-P. Majoral, Mol. Pharm. 2017, 14, 40874097

[226] a) A. Perez-Anes, S. Mazeres, A. M. Caminade, M. Blanzat, C. O Turrin, Tetrahedron Lett. 2015, 56, 1566-1569; b) A. Perez-Anes, F. Rodrigues, A. M. Caminade, C. Stefaniu, B. Tiersch, C. O. Turrin, M. Blanzat, ChemPhysChem 2015, 16, 3433-3437.

[227] J. Ledall, S. Fruchon, M. Garzoni, G. M. Pavan, A. M. Caminade, C. O. Turrin, M. Blanzat, R. Poupot, Nanoscale 2015, 7, 17672-17684.

[228] a) S. Fruchon, M. Poupot, L. Martinet, C. O. Turrin, J. P. Majoral, J. J. Fournie, A. M. Caminade, R. Poupot, J. Leukocyte Biol. 2009, 85, 553562; b) Y. Degboe, S. Fruchon, M. Baron, D. Nigon, C. O. Turrin, A. M. Caminade, R. Poupot, A. Cantagrel, J. L. Davignon, Arthritis Research \& Therapy 2014, 16

[229] D. Portevin, M. Poupot, O. Rolland, C. O. Turrin, J. J. Fournie, J. P. Majoral, A. M. Caminade, R. Poupot, J. Transl. Med. 2009, 7, 13.

[230] M. Poupot, C. O. Turrin, A. M. Caminade, J. J. Fournie, M. Attal, R. Poupot, S. Fruchon, Nanomedicine-Nanotechnology Biology and Medicine 2016, 12, 2321-2330.

[231] M. Hayder, M. Garzoni, D. Bochicchio, A.-M. Caminade, F. Couderc, V Ong-Meang, J.-L. Davignon, C.-O. Turrin, G. M. Pavan, R. Poupot, Biomacromolecules 2018, 19, 712-720.

[232] M. Hayder, M. Poupot, M. Baron, D. Nigon, C. O. Turrin, A. M. Caminade, J. P. Majoral, R. A. Eisenberg, J. J. Fournie, A. Cantagrel, R. Poupot, J. L. Davignon, Sci. Transl. Med. 2011, 3, 11.

[233] S. Fruchon, A. M. Caminade, C. Abadie, J. L. Davignon, J. M. Combette, C. O. Turrin, R. Poupot, Molecules 2013, 18, 9305-9316.

[234] M. Hayder, M. Varilh, C. O. Turrin, A. Saoudi, A. M. Caminade, R. Poupot, R. S. Liblau, Biomacromolecules 2015, 16, 3425-3433.

[235] S. Fruchon, S. Mouriot, T. Thiollier, C. Grandin, A. M. Caminade, C. O. Turrin, H. Contamin, R. Poupot, Nanotoxicology 2015, 9, 433-441. 


\section{Entry for the Table of Contents}

Layout 2:

\section{MICROREVIEW}

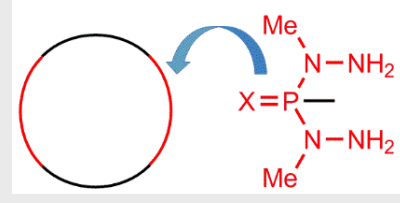

$\mathrm{H}_{2} \mathrm{~N}-\mathrm{N}$<smiles>[X]P(C)(C)(C)N(C)N</smiles>

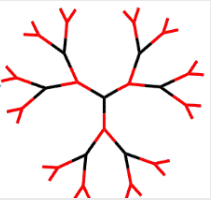

The condensation reactions of phosphorhydrazide linkages with aldehydes have been successfully used for the synthesis of special macromolecular architectures such as macrocycles and dendrimers.
Macrocycles, dendrimers ${ }^{\star}$

Jean-Pierre Majoral, Anne-Marie

Caminade*

Page No. - Page No.

Phosphorhydrazones as useful building-blocks for special architectures: macrocycles and dendrimers. 